OPEN ACCESS

Edited by:

Dominic C. Voon,

Kanazawa University, Japan

Reviewed by:

Joseph William Landry, Virginia Commonwealth University,

United States

Shang Li,

Duke-NUS Medical School,

Singapore

*Correspondence:

Glen Reid

glen.reid@otago.ac.nz

Specialty section:

This article was submitted to

Cell Growth and Division,

a section of the journal

Frontiers in Cell and Developmental

Biology

Received: 26 July 2019 Accepted: 18 September 2019

Published: 01 October 2019

Citation:

Johnson TG, Schelch K, Mehta S,

Burgess A and Reid G (2019) Why Be

One Protein When You Can Affect

Many? The Multiple Roles of YB-1

in Lung Cancer and Mesothelioma.

Front. Cell Dev. Biol. 7:221.

doi: 10.3389/fcell.2019.00221

\section{Why Be One Protein When You Can Affect Many? The Multiple Roles of YB-1 in Lung Cancer and Mesothelioma}

\author{
Thomas G. Johnson ${ }^{1,2,3,4}$, Karin Schelch ${ }^{5}$, Sunali Mehta ${ }^{6,7}$, Andrew Burgess ${ }^{2,3}$ and \\ Glen Reid6,7* \\ ${ }^{1}$ Asbestos Diseases Research Institute, Sydney, NSW, Australia, ${ }^{2}$ Cell Division Laboratory, The ANZAC Research Institute, \\ Sydney, NSW, Australia, ${ }^{3}$ School of Medicine, The University of Sydney, Sydney, NSW, Australia, ${ }^{4}$ Sydney Catalyst \\ Translational Cancer Research Centre, The University of Sydney, Sydney, NSW, Australia, ${ }^{5}$ Institute of Cancer Research, \\ Medical University of Vienna, Vienna, Austria, ${ }^{6}$ Department of Pathology, University of Otago, Dunedin, New Zealand, \\ ${ }^{7}$ Maurice Wilkins Centre, University of Otago, Dunedin, New Zealand
}

Lung cancers and malignant pleural mesothelioma (MPM) have some of the worst 5year survival rates of all cancer types, primarily due to a lack of effective treatment options for most patients. Targeted therapies have shown some promise in thoracic cancers, although efficacy is limited only to patients harboring specific mutations or target expression. Although a number of actionable mutations have now been identified, a large population of thoracic cancer patients have no therapeutic options outside of first-line chemotherapy. It is therefore crucial to identify alternative targets that might lead to the development of new ways of treating patients diagnosed with these diseases. The multifunctional oncoprotein Y-box binding protein-1 (YB-1) could serve as one such target. Recent studies also link this protein to many inherent behaviors of thoracic cancer cells such as proliferation, invasion, metastasis and involvement in cancer stem-like cells. Here, we review the regulation of YB-1 at the transcriptional, translational, posttranslational and sub-cellular levels in thoracic cancer and discuss its potential use as a biomarker and therapeutic target.

Keywords: lung cancer, mesothelioma, targeted therapy, biomarker, Y-box binding protein-1

\section{INTRODUCTION}

Lung cancers are the leading cause of cancer death worldwide (Islami et al., 2015; Kris et al., 2017), and malignant pleural mesothelioma patients continue to experience some of the worst 5 -year survival rates of all malignancies (Mutti et al., 2018). Therefore, advances in therapeutic options are urgently needed and require a more thorough understanding of the underlying biology of both.

While SCLC represents $\sim 15-20 \%$ of all lung cancers, NSCLC represent the majority of cases $(\sim 80-85 \%)$. NSCLC are further subtyped into adenocarcinomas (ADC; $\sim 40-50 \%$ of NSCLC), squamous cell carcinomas (SCC; $\sim 20-40 \%$ ) and large cell carcinomas (LGC; $\sim 20 \%$ ). Whilst all of these carcinomas are significantly associated with tobacco consumption, this association is much stronger in SCLC and SCC than in ADC and LGC (Khuder, 2001). 
Malignant pleural mesothelioma arises from the pleural linings of the lung and is strongly linked to asbestos exposure (Tossavainen, 2004). MPM is currently subtyped as epithelioid, sarcomatoid or biphasic, which are characterized by a mixture of epithelioid and sarcomatoid cells (Marshall et al., 2015). At times, this review refers to lung cancer and mesothelioma as "thoracic cancers," although we acknowledge that this term also encompasses tumors of the trachea, esophagus and thymus.

The current clinical practice guidelines for NSCLC, SCLC, and MPM all recommend the use of platinum-based chemotherapy in combination with other agents as the standard mode of care (Vogelzang et al., 2003; Rudin et al., 2016; Bradbury et al., 2017; Kris et al., 2017; Nagasaka and Gadgeel, 2018; Szolkowska et al., 2018). Diagnosis in the early stages of NSCLC affords better survival odds, however, the majority of patients are diagnosed with advanced disease (Kris et al., 2017; Visconti et al., 2017). Such individuals face a 5-year survival rate of only $23 \%$ and treatment options are often limited to chemotherapy (Kris et al., 2017). SCLC patients face similarly poor survival odds. Patients usually respond initially to platinum-based chemotherapy but inevitably develop chemoresistant tumors (Rudin et al., 2016). Overall survival rates of SCLC patients currently sit at 10-12 months post diagnosis (Rudin et al., 2016). In MPM, the standard of care consists of a combination of cisplatin with pemetrexed, providing an overall survival rate of only 12.1 months (Vogelzang et al., 2003; Mutti et al., 2018). Epithelioid mesotheliomas present with the best prognosis, with the median overall survival being between 12 and 27 months (Yap et al., 2017). Patients with biphasic mesothelioma have median overall survival rates of 718 months, while sarcomatoid patients are afforded the worst prognosis of 4-12 months (Yap et al., 2017). Recent trials of immunotherapy strategies, such as the anti-PD-1 checkpoint inhibitors pembrolizumab and nivolumab, have shown promise as first-line and second-line therapies in some thoracic cancers (Visconti et al., 2017; Forde et al., 2019). However, response to immunotherapy is unpredictable due to a lack of robust biomarkers, so predicating which patients will respond is not yet possible (Ventola, 2017). Acquired resistance to these drugs also remains a significant problem (Ventola, 2017). Improved treatment options for patients suffering malignancies of the lung and mesothelial linings are therefore still desperately needed.

\section{Toward Personalized Therapy for Thoracic Cancer Patients}

The development of next-generation sequencing has fostered a deeper understanding of the molecular drivers and mutational landscape of thoracic cancers. Multi-region whole-exome sequencing of 100 early stage NSCLC patients demonstrated that clonal alterations of oncogenes such as the growth receptor EGFR and the kinases MET, and BRAF were commonly found in ADC (Jamal-Hanjani et al., 2017). These were accompanied by sub-clonal modifications of the oncogene PIK3CA and the tumor suppressor neurofibromin 1 (Jamal-Hanjani et al., 2017). Alterations of PIK3CA, the transmembrane receptor NOTCH1, growth factor receptor FGFR1 and transcription factor SOX2 were also observed in early SCC (Jamal-Hanjani et al., 2017). TP53 or p53 mutations were frequent clonal events in both subtypes, while oncogenic $A L K$ translocations were not observed in any tumors (Jamal-Hanjani et al., 2017).

As for MPM, next-generation sequencing of $216 \mathrm{MPM}$ patients showed that the tumor suppressors BAP1, NF2, and SETD2 were significantly mutated through gene fusions and splicing alterations (Bueno et al., 2015). CDKN2A, which encodes the tumor suppressor $\mathrm{p} 16^{\mathrm{INK} 4 \mathrm{a}}$, is also frequently deleted in up to $75-90 \%$ of MPM cases (Ladanyi, 2005; Sementino et al., 2018). Data from TCGA reflects the above findings, apart from $A L K$ alterations in ADC, which were present in $7 \%$ of cases (Figures 1A-C). An important distinction must between lung cancer and MPM is that lung cancers are generally characterized by an increase in oncogenic drivers, while MPM appears to be more commonly defined by loss of tumor suppressors (Ladanyi, 2005; Bueno et al., 2015; Jamal-Hanjani et al., 2017; Figure 1C). This makes identifying new therapeutic targets in MPM more challenging. Apart from bevacizumab, which targets vascular endothelial growth factor A, no targeted therapies are currently available to MPM patients (Brosseau et al., 2017). 

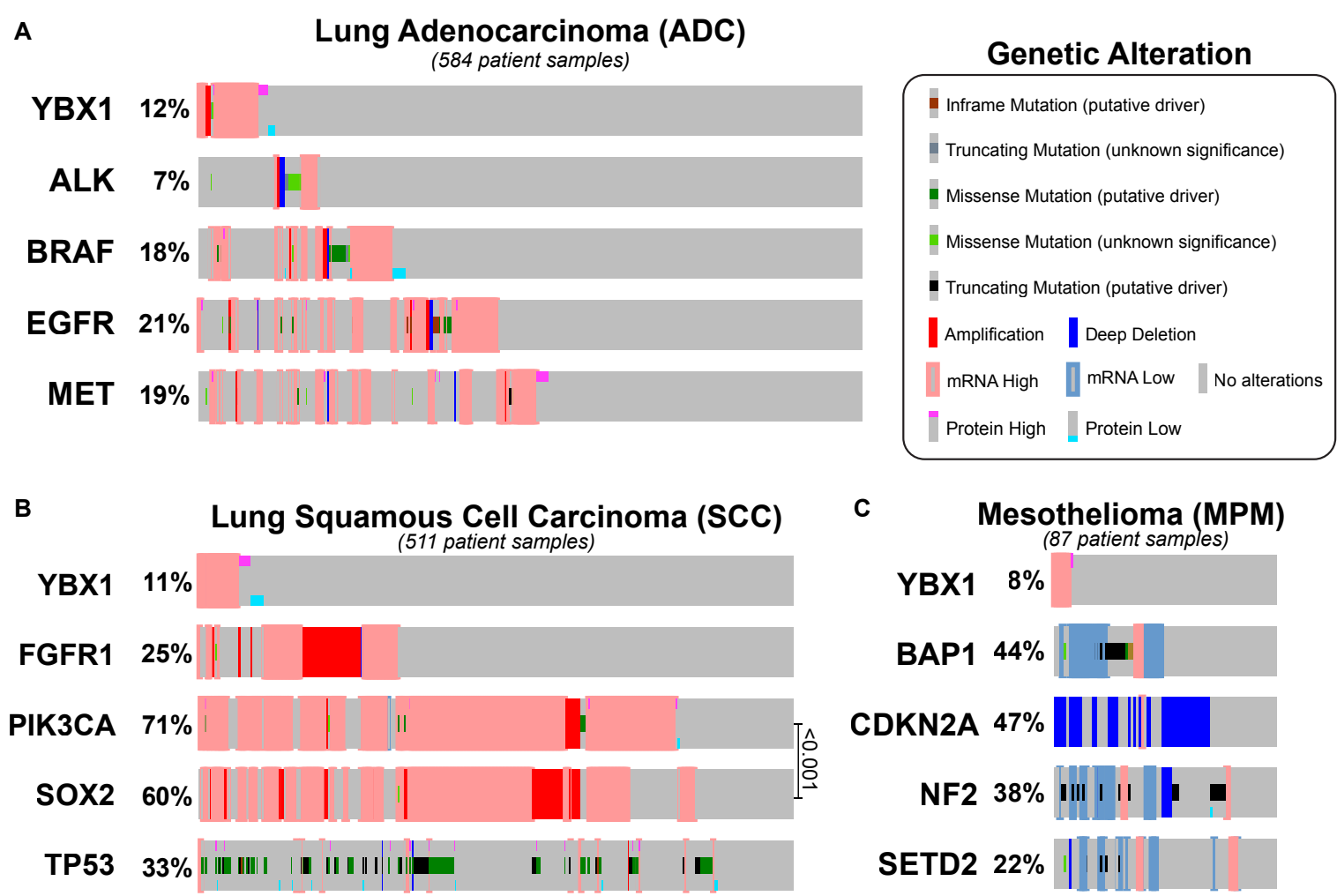

D

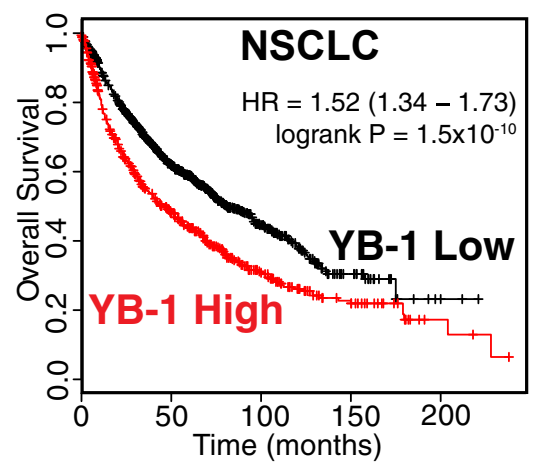

E

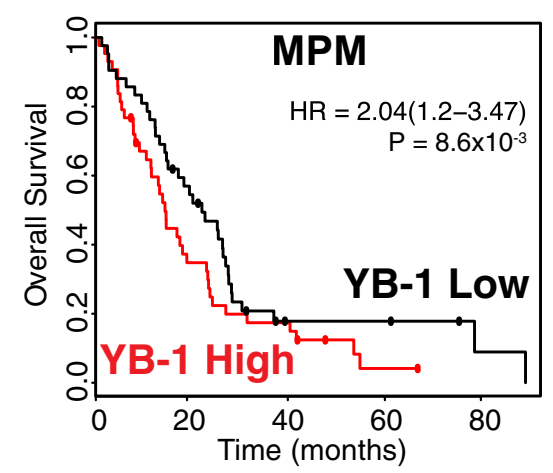

FIGURE 1 | YB-1 is altered in NSCLC (ADC and SCC) and MPM patients and high YBX1 mRNA expression correlates with poor prognosis in both diseases. Reported alteration frequencies of $Y B X 1$ and commonly altered genes in current TCGA Provisional datasets for all complete tumors with RNASeq V2 RSEM mRNA and RPPA protein Expression for (A) Lung Adenocarcinoma (ADC; $n=584$ ), (B) Lung Squamous Cell Carcinoma (SCC; $n=511$ ) and (C) Mesothelioma (MPM; $n=87$ ). Panels $(\mathbf{A}-\mathbf{C})$ were adapted from the open-source platform cBioPortal for Cancer Genomics (cBioPortal.org). (D) High YBX1 expression correlates with poor prognosis in NSCLC patients $\left(p=1.5 \times 10^{-10}\right)$. Kaplan-Meir plot of 1,926 NSCLC patients generated using Lung Cancer KM plotter. Univariate analysis with probe set 20862_S_at (YBX1) using auto-selected cutoff and excluded biased arrays. (E) High YBX1 expression correlates with poor prognosis in MPM patients $\left(p=8.6 \times 10^{-3}\right)$. Kaplan-Meir plot was generated using PROGgene V2 with the TCGA mesothelioma dataset $(n=83)$ using "DEATH" as the survival measure and median as the cutoff.

The story for SCLC patients is similar with no breakthrough changes in treatment in over 25 years despite decades of research. The only exception to this is the approval of topotecan as a second-line therapy (Hirsch et al., 2017), and immunotherapy, which has shown some promise in Phase I/II trials in PD-L1 positive relapsed SCLC patients (Ott et al., 2015). Unfortunately, immunotherapy success has been limited by rapid disease progression, which can result in patient death before an effective anti-tumor response has time to occur (3-6 months), and severe immuno-related toxicities (encephalitis or myasthenia gravis) that are already highly associated with SCLC (Oronsky et al., 2017). Other drugs such as PARP inhibitors and 
transcription inhibitors have shown some preclinical promise, but have yet to translate into clinical benefits for SCLC patients (Oronsky et al., 2017).

For NSCLC, targeted therapies have provided promising, albeit limited, results. The best known of these are the EGFR tyrosine kinase inhibitors such as erlotinib and osimertinib, which have proved effective for EGFR mutant ADC tumors (Hirsch et al., 2017; Winther-Larsen et al., 2019). In the ADC TCGA dataset, $21 \%$ of patients had EGFR alterations (Figure 1A), although the occurrence of EGFR mutations can vary between populations in ADC and NSCLC as a whole. For example, while EGFR mutation can occur in up to $40 \%$ of all NSCLC patients of Asian descent, the frequency of mutation in non-Asian NSCLC populations drops to 10-20\% (Hirsch et al., 2017). Another problem is that response to EGFR inhibitors is almost always followed by the emergence of resistance (Hirsch et al., 2017). ALK inhibitors are similarly effective in patients harboring ALK translocations (Hirsch et al., 2017), present in 2\% of all NSCLC patients (Hirsch et al., 2017). Alterations of ALK in ADC tumors specifically is found in up to $7 \%$ of cases, according to TCGA data (Figure 1A). Inhibitors targeting BRAF mutant tumors (3-5\% of lung cancers), MET overexpressing tumors (3$4 \%$ of ADC cases) and tumors harboring RET fusion proteins (1-2\% of NSCLC) are also currently undergoing preclinical and clinical studies (Hirsch et al., 2017). The remaining majority of patients with ADC have no known actionable targets.

Patients with SCC have even fewer options with only $~ 13 \%$ of SCC tumors reported to harbor at least one currently actionable alteration (Lindquist et al., 2017). There is no subset of patients known to benefit from targeted drugs at the moment, although there is some benefit from immunotherapy (Hirsch et al., 2017; Friedlaender et al., 2019). TP53 mutations are a common alteration in SCC patients (33\%; Figure 1B), however, existing targeted TP53 treatments have proven ineffective (Friedlaender et al., 2019). PIK3CA is also frequently altered in thoracic cancer, particularly in SCC (Friedlaender et al., 2019) (71\%; Figure 1B), indicating that it may have significance as a therapeutic target. However, despite promising preclinical studies of PIK3CA inhibitors, the benefit of these drugs appears to be negligible in trials with NSCLC patients (Friedlaender et al., 2019). This has also been the case in other cancers where, generally, patients show limited response and many experience prohibitive toxicity (Janku et al., 2018). This pathway mediates a multitude of downstream effects, which may attest to the observed relative ineffectiveness of PIK3CA inhibitors in lung cancer. FGFR1 amplification occurs in 20-25\% of SCC cases (Friedlaender et al., 2019; Figure 1B), but again, targeting it in the clinic has provided limited efficacy and its potential as a viable target remains under contention (Hirsch et al., 2017; Friedlaender et al., 2019). There are a few targets that have been the focus of preclinical studies showing promising results, such as the transcription factor SOX2. SOX2 is involved in cell lineage-survival (Friedlaender et al., 2019) and is often upregulated in SCC (Karachaliou et al., 2013; Friedlaender et al., 2019) (60\%; Figure 1B), as well as SCLC (Rudin et al., 2012; Karachaliou et al., 2013) and to a lesser degree ADC (Karachaliou et al., 2013). Finding such targets and translating them to the clinic is essential to improve outcomes for patients with SCC.
The heterogeneity of thoracic cancer biology makes finding clinically relevant therapeutic targets inherently difficult. Identifying other penetrant driver events in thoracic cancers may uncover alternative targets, which could yield more therapeutic options for patients down the line. One such potential target is YB-1. YB-1 is downstream of the commonly dysregulated PI3K-AKT-mTOR pathway, so targeting it may refine the effects of inhibiting this signal cascade. Thus, anti-YB-1 agents may provide more tumor-specific results than their upstreamtargeting counterparts, such as PIK3CA inhibitors (Janku et al., 2018). Adding to this, YB-1 upregulates PIK3CA at the transcriptional level in breast cancer (Astanehe et al., 2009). This implies that YB-1 may be involved in a feed-forward loop with the PI3K-AKT pathway and that targeting it could be an effective strategy in tumors with heightened PIK3CA, such as SCC. YB-1 is also upstream of SOX2 (Jung et al., 2014) and a host of other oncogenic drivers (Lasham et al., 2013), so the downstream effects of YB-1 inhibition may still be broad enough to make it an interesting candidate. This review therefore outlines recent literature focusing on YB-1 in cancer and makes the case for its possible use as a biomarker and future therapeutic target in thoracic malignancies.

\section{Y-Box Binding Protein-1 in Thoracic Cancers: An Overlooked Target?}

Y-box binding protein-1, encoded by the $Y B X 1$ gene, is a multifunctional oncoprotein involved in many hallmarks of cancer development including driving proliferation, invasion and metastasis, CSC biology, resistance to chemotherapy, hypoxic response, DNA repair and exosomal sorting. Despite these links YB-1 has received limited attention as a therapeutic target or biomarker in oncology (Lasham et al., 2013). Although mutations of $Y B X 1$ are rare [ $1 \%$ in all cancers types (Cerami et al., 2012; Gao et al., 2013)], overexpression of YB-1 is found in a wide range of cancers and is often associated with poor prognosis (Lasham et al., 2013), including NSCLC and MPM. Analysis of TCGA data shows that elevated $Y B X 1$ expression was highly prognostic in a cohort of 1,926 NSCLC patients (Györffy et al., 2013; Figure 1D) and in 83 mesothelioma patients (Goswami and Nakshatri, 2014; Figure 1E). This supports the results of a recent meta-analysis of data from 692 NSCLC patients which found that high YB1 protein expression significantly correlated with poorer overall survival and clinicopathological features (Jiang et al., 2017). YB1 is overexpressed in mesothelioma compared to non-malignant mesothelial cells in vitro (Johnson et al., 2018) and a small study of 33 MPM patients showed a trend toward higher YB-1 expression in sarcomatoid MPM tumors, which are associated with shorter survival (Iwanami et al., 2014). Unfortunately, TCGA data is currently not available for SCLC, likely because surgically resected tissue specimens are relatively rare (Byers and Rudin, 2015) and, to our knowledge, a prognostic study on YB-1 expression in SCLC is yet to be conducted.

In the above datasets, alterations were seen in 12,11 , and $8 \%$ in ADC, SCC, and MPM, respectively, and mRNA upregulation was predominant (Figures 1A-C). While only PIK3CA and SOX2 were significantly co-expressed in the SCC dataset $(q<0.001$; 
Figure 1B), notably, this analysis did not show $Y B X 1$ alteration to be significantly associated with the current targetable oncogenes $A L K, B R A F$ or EGFR in ADC (Figure 1A), despite there being a small proportion of tumors that had elevated levels of both $Y B X 1$ and EGFR. This suggests that YB-1 deregulation may represent a unique subpopulation of patients that may not have a targetable mutation. This combined with the prognostic significance of YB1 in NSCLC and MPM, suggests that YB-1 may be a clinically relevant target worthy of further investigation.

\section{YB-1: A MALIGNANT JACK OF ALL TRADES}

\section{A Driver of Malignant Phenotypes}

Y-box binding protein-1 was first discovered as a negative transcriptional factor of major histocompatibility complex Class II where it binds to the Y-box (5'-CTGATTGG-3') (Didier et al., 1988). Further investigation found that YB-1 stimulated the transcription of a wide variety of genes, including important oncogenes such as EGFR and HER2 (Lasham et al., 2013). YB1 is a part of the cold-shock protein superfamily and contains a conserved nucleic acid binding region termed the CSD (Wolffe et al., 1992; Figure 3). Along with the CSD, YB-1 is comprised of two other highly disordered domains, the alanine/proline rich variable $\mathrm{N}$-terminal domain and the $\mathrm{C}$-terminal domain (CTD), each facilitating different biological interactions (Lyabin et al., 2014; Suresh et al., 2018). This versatility affords YB-1 a range of functions including transcriptional regulation, DNA repair and pre-mRNA splicing (Lyabin et al., 2014). YB-1 is also a major component of messenger ribonucleoprotein complexes and is integrally involved in mRNA stabilization and the translational activation or repression of many genes (Suresh et al., 2018). This assortment of functions manifest themselves in an equally broad spectrum of biological roles in cancer (Lasham et al., 2013; Lyabin et al., 2014). The general cancer-related activities of YB-1 have been previously reviewed (Lasham et al., 2013; Kosnopfel et al., 2014; Lyabin et al., 2014) and therefore we will primarily focus on recent publications on the role of YB1 specifically in lung cancer and MPM here. The evidence supporting each phenotype driven by YB-1 and the relevant interaction partners for the following sections is summarized in Table 1.

\section{A Promoter of Cell Proliferation and Cell Cycle Progression}

The proliferative role of YB-1 in cancer has been demonstrated in many malignancies, driven by its regulation of highly penetrant downstream oncogenic growth promoting genes (Lasham et al., 2013). A prime example is the transcriptional activation of EGFR by YB-1. A study of 105 NSCLC samples showed that YB-1 and EGFR were significantly co-expressed and knockdown of YB-1 in two NSCLC cell lines resulted in reduction of EGFR (Hyogotani et al., 2012). Similar results have also been observed in basallike breast cancer and spinal chordoma (Stratford et al., 2007; Liang et al., 2019). Notably, overexpression of EGFR in lung cancer and mesothelioma promotes cell growth, invasion and angiogenesis (Ciardiello et al., 2004; Destro et al., 2006). Several cell cycle regulators are also under YB-1 control, including the E2F family. YB-1 specifically binds to the promoter of cell cycle activators transcription factor $E 2 F 1$ and transcription factor E2F2 and YB-1 knockdown reduced cell proliferation of a NSCLC cell line in vitro and in vivo (Lasham et al., 2011). In NSCLC cells, YB-1 transcriptionally activates CCND1 a protein critical for progression through the G1 phase (Harada et al., 2014). YB1 also binds to and activates the promoter of the dual specific phosphatase CDC25A, driving G1/S cell cycle progression (Zhao et al., 2016). These studies demonstrate the important role of YB1 by showing that its knockdown with siRNA induces G0/G1 cell cycle arrest in vitro and in vivo (Harada et al., 2014; Zhao et al., 2016). Similarly, we have also shown that targeting YB1 with siRNA can inhibit the growth of MPM cells in vitro (Johnson et al., 2018).

Y-box binding protein-1-driven proliferation may require a region within its $\mathrm{N}$-terminal domain. Breast cancer cells overexpressing a YB-1 CTD fragment (from amino acid 125 onward) exhibited proliferation inhibition in vitro and in vivo (Shi et al., 2016). It is possible that the removal of Ser102, a site commonly phosphorylated and associated with growth (discussed further in section "Post-Translational Modification in the Control of YB-1 Activity and Localization"), could explain the lack of growth promotion here. However, as growth was actively inhibited in response to the upregulation of the YB-1 CTD, this could also suggest that YB-1, or certain regions of it, may inhibit proliferation under specific gene dosages or biological contexts. For example, YB-1 overexpression in Ras-MAPK activated breast cancer cells led to YB-1-mediated translational repression of growth-promoting genes, lowering proliferation rates. This was accompanied by the induction of EMT-like changes which promoted migration, invasion and allowed cells to survive in anchorage-independent conditions (Evdokimova et al., 2009b). This suggests that YB-1 expression levels determine its function, driving either a proliferative or invasive phenotype.

\section{YB-1 Is a Central Player in EMT, Invasion and Metastasis}

Invasion and metastasis are key behaviors of lung cancer and mesothelioma cells that contribute to patient death and the poor prognosis observed with these tumors. YB-1 is known to play a role in the migration of thoracic cancer cells. Stable overexpression of YB-1 in lung ADC cells induced E-cadherin downregulation, N-cadherin upregulation, accelerated TGF $\beta 1$ induced EMT and cell migration (Ha et al., 2015). In support, silencing YB-1 inhibited the invasion and metastasis of lung cancer cells in vitro and in vivo (Guo et al., 2017). YB-1 overexpression also significantly increased the invasive capacity of these cells in vitro (Guo et al., 2017). Similarly, knockdown of YB-1 inhibited lung cancer migration (Zhao et al., 2016) and MPM migration and invasion (Johnson et al., 2018) in vitro. YB-1 has also been implicated in the migration and invasion of breast cancer (Lim et al., 2017), melanoma (Jia et al., 2017), nasopharyngeal cancer (Zhou et al., 2017b), skin squamous 
TABLE 1 | Roles and interaction partners of YB-1 related to thoracic cancer biology.

\begin{tabular}{|c|c|c|c|}
\hline Phenotype & Role in thoracic cancer behavior & Targets or interactions & Other cancers/evidence \\
\hline $\begin{array}{l}\text { Proliferation and cell cycle } \\
\text { progression }\end{array}$ & $\begin{array}{l}\text { Knockdown induces growth inhibition } \\
\text { of NSCLC (Harada et al., 2014; Zhao } \\
\text { et al., 2016) and MPM (Johnson et al., } \\
\text { 2018) }\end{array}$ & $\begin{array}{l}\text { Transcriptional regulation of EGFR } \\
\text { (Hyogotani et al., 2012), E2F family } \\
\text { members (Lasham et al., 2011), } \\
\text { CCND1 (Harada et al., 2014) and } \\
\text { CDC25A (Zhao et al., 2016) }\end{array}$ & $\begin{array}{l}\text { Basal-like breast cancer (Stratford } \\
\text { et al., 2007) spinal chordoma (Liang } \\
\text { et al., 2019) }\end{array}$ \\
\hline $\begin{array}{l}\text { Migration, EMT, invasion and } \\
\text { metastasis }\end{array}$ & $\begin{array}{l}\text { Overexpression in lung ADC promotes } \\
\text { E- to N-cadherin shift, EMT and } \\
\text { migration (Ha et al., 2015) } \\
\text { Knockdown inhibits invasion and } \\
\text { metastasis of lung cancer cells (Zhao } \\
\text { et al., 2016; Guo et al., 2017) } \\
\text { Knockdown inhibits migration and } \\
\text { invasion of MPM cells (Johnson et al., } \\
\text { 2018) }\end{array}$ & $\begin{array}{l}\text { Translational activation of SNA/1 } \\
\text { (Evdokimova et al., 2009a,b) } \\
\text { Involvement in E/M related Wnt } \\
\text { signaling - } \beta \text {-catenin (Chao et al., 2017) }\end{array}$ & $\begin{array}{l}\text { Breast cancer (Lim et al., 2017), } \\
\text { melanoma (Jia et al., 2017), } \\
\text { nasopharyngeal cancer (Zhou et al., } \\
\text { 2017b), skin squamous cell carcinoma } \\
\text { (Wang W. et al., 2017) spinal chordoma } \\
\text { (Liang et al., 2019) } \\
\text { Overexpression induces E/M } \\
\text { phenotype (Gopal et al., 2015) }\end{array}$ \\
\hline Cancer stem-like cells & $\begin{array}{l}\text { Drives metastatic CSC-like properties in } \\
\text { lung cancer (Guo et al., 2017) }\end{array}$ & $\begin{array}{l}\text { Transcriptional regulation of SOX2 } \\
\text { (Jung et al., 2014; Bledzka et al., 2017), } \\
\text { NANOG (Bledzka et al., 2017; Chao } \\
\text { et al., 2017; Guo et al., 2017) and Oct4 } \\
\text { (Bledzka et al., 2017; Chao et al., 2017) }\end{array}$ & $\begin{array}{l}\text { Hepatocellular carcinoma (Chao et al., } \\
\text { 2017), brain (Mantwill et al., 2013), } \\
\text { osteosarcoma (Xu et al., 2015), and } \\
\text { breast (Davies et al., 2015) CSCs }\end{array}$ \\
\hline Hypoxic response & Requires further investigation & $\begin{array}{l}\text { Translational regulation of } \\
\text { HIF1 } \alpha(\text { El-Naggar et al., 2015) and } \\
\text { FOXO3a (Emerling et al., 2008; Chou } \\
\text { et al., 2015) } \\
\text { Transcriptional repression of EPO } \\
\text { (Rauen et al., 2016) }\end{array}$ & $\begin{array}{l}\text { Translocation to nucleus under hypoxic } \\
\text { stress (Rauen et al., 2016) }\end{array}$ \\
\hline $\begin{array}{l}\text { LRP downregulation after YB-1 } \\
\text { knockdown and correlation with } \\
\text { LRP (Hyogotani et al., 2012) } \\
\text { response }\end{array}$ & $\begin{array}{l}\text { LRP downregulation after YB-1 } \\
\text { knockdown and correlation with LRP } \\
\text { (Hyogotani et al., 2012) }\end{array}$ & $\begin{array}{l}\text { Transcriptional regulation of LRP (Stein } \\
\text { et al., 2005) and MRP1 (Stein et al., } \\
\text { 2001; Mantwill et al., 2006) }\end{array}$ & $\begin{array}{l}\text { Neuroblastoma (Wang H. et al., 2017), } \\
\text { esophageal SCC (Xu and Hu, 2016), } \\
\text { bladder cancer (Shiota et al., 2011), } \\
\text { melanoma (Schittek et al., 2007), } \\
\text { ovarian cancer (Yahata et al., 2002) }\end{array}$ \\
\hline DNA repair & $\begin{array}{l}\text { Involved in cigarette-smoke induced } \\
\text { guanine oxidization prevention and } \\
\text { correlations in COPD patients (Deslee } \\
\text { et al., 2010) }\end{array}$ & $\begin{array}{l}\text { Complex with PCNA at } \\
\text { cisplatin-modified DNA (Ise et al., 1999; } \\
\text { Gaudreault et al., 2004) } \\
\text { PARP1 poly(ADP-ribosyl)ation of YB-1 } \\
\text { (Alemasova et al., 2015) } \\
\text { Scaffold for BER proteins (Dutta et al., } \\
\text { 2015; Alemasova et al., 2016) } \\
\text { Scaffolds for XPC (NER protein) } \\
\text { (Fomina et al., 2015) }\end{array}$ & $\begin{array}{l}\text { Preferential binding to } \\
\text { cisplatin-modified DNA (Ise et al., 1999) }\end{array}$ \\
\hline Exosomes & Requires further investigation & $\begin{array}{l}\text { ncRNA (Shurtleff et al., 2017; Suresh } \\
\text { et al., 2018) }\end{array}$ & $\begin{array}{l}\text { Presence in non-malignant and } \\
\text { malignant exosomes (Shurtleff et al., } \\
\text { 2017; Suresh et al., 2018) } \\
\text { Role in exosomal ncRNA sorting } \\
\text { (Shurtleff et al., 2017; Suresh et al., } \\
\text { 2018) }\end{array}$ \\
\hline
\end{tabular}

cell carcinoma (Wang W. et al., 2004) and spinal chordoma (Liang et al., 2019).

Epithelial-mesenchymal transition is thought to be a primary mechanism facilitating cancer cell invasion and metastasis through inducing phenotypic plasticity (Brabletz, 2012). Current evidence suggests that EMT is a progressive, transient and reversible process and that cells in a hybrid $\mathrm{E} / \mathrm{M}$ state - partial EMT - exhibit significantly higher tumorigenic potential compared to exclusively epithelial or mesenchymal cells (Pastushenko et al., 2018; Kröger et al., 2019).

Hybrid epithelial/mesenchymal state hybrids can be promoted by Zinc finger protein SNAI1 (Snail, gene SNAI1) transcription factor activity, the expression of which is specific to $\mathrm{E} / \mathrm{M}$ populations of basal breast cancer cells (Kröger et al., 2019). Snail protein was found to be 5-fold higher in such cells compared to mesenchymal populations, while epithelial cells displayed undetectable levels (Kröger et al., 2019). However, this was only accompanied by a 1.5 -fold increase in SNAI1 transcript expression, implying that translational activation is more important in Snail overexpression than transcriptional regulation (Kröger et al., 2019). YB-1 translationally upregulates Snail expression (Evdokimova et al., 2009a,b), suggesting that YB1 could also be a key promoter the E/M state. In support, stable YB-1 overexpressing epithelial Madin-Darby canine kidney $\left(\mathrm{MDCK}^{\mathrm{YB}-1}\right)$ cells exhibited a partial EMT-like phenotype and establish viable tumor xenografts in mice, while parental MDCK 
cells did not (Gopal et al., 2015). This increased tumorigenicity was also accompanied by elevated secretion of angiogenic factors (Gopal et al., 2015). Treatment of endothelial cells with concentrated conditioned medium from $\mathrm{MDCK}^{\mathrm{YB}-1}$ cells also stimulated cell migration (Gopal et al., 2015).

Wnt signaling is also a primary driver of partial and complete EMT. $\beta$-catenin-dependent canonical Wnt signaling is thought to be preferentially active in E/M populations (Reya and Clevers, 2005; Kröger et al., 2019), while $\beta$-catenin-independent noncanonical signaling is more associated with a mesenchymal state, migration and invasion (Weeraratna et al., 2002; Gujral et al., 2014). Knockdown of YB-1 in hepatocellular carcinoma cells disrupted stemness and suppressed $\beta$-catenin protein expression and nuclear translocation, which was rescued by overexpression of the active form of $\beta$-catenin (Chao et al., 2017). This regulation of $\beta$-catenin-dependent Wnt signaling further supports a potential role for YB-1 in driving a partial EMT state. Interestingly, populations in the partial EMT state are also enriched with CSCs (Kröger et al., 2019), suggesting that YB-1 may also play are role in regulating these important cancer progenitors.

\section{Involvement in Cancer Stem-Like Cells}

Cancer stem-like cells are becoming recognized as important drivers of disease progression and are thought to be a major contributing factor toward metastasis, the development of drug resistance and recurrence of most cancers, including those of the thorax (Leon et al., 2016; MacDonagh et al., 2016; Makena et al., 2018). CSCs are a heterogeneous, slow growing population of cells within a tumor. They have selfrenewal ability but one subpopulation, termed metastatic CSCs, can disseminate through blood vessels and initiate metastasis (Dalerba and Clarke, 2007). This was clearly demonstrated in pancreatic cancer, where eradicating the metastatic CSC population dramatically reduced metastatic but not tumorigenic potential, implying that a subgroup of CSCs are responsible for metastasis (Hermann et al., 2007).

One recent study has shown that YB-1 enforces lung cancer metastatic CSC-like properties in vitro and in vivo through transcriptional upregulation of NANOG, a marker of CSCs required for the invasion and sphere formation of ADC cells in vitro (Guo et al., 2017). Supporting this, knockdown of YB-1 in hepatocellular carcinoma cells reduced NANOG and Oct4, as well as $\alpha$-fetoprotein transcript expression (Chao et al., 2017). This follows findings showing NANOG and Oct4 are upregulated in ADC, which induce sphere formation, drug resistance and EMT (Chiou et al., 2010). YB-1 also regulates SOX2 in breast CSCs, maintaining stemlike properties and tumorigenic potential (Jung et al., 2014). Given the probable importance and frequent upregulation of SOX2 in lung cancer (Rudin et al., 2012; Karachaliou et al., 2013; Friedlaender et al., 2019; Figure 1B), a study investigating the relationship between YB-1 and SOX2 in thoracic cancer may further implicate YB-1 in the biology of these diseases.

Y-box binding protein-1 has been shown to be important in other cancer CSCs as well. Brain CSCs were shown to have high expression of YB-1 which was utilized in a YB1-based virotherapy in vitro (Mantwill et al., 2013). The reexpression of the microRNA miR-382 in osteosarcoma cells significantly decreased the CSC population resulting in reduced relapse after doxorubicin treatment, EMT and metastasis both in vitro and in vivo ( $\mathrm{Xu}$ et al., 2015). The authors attributed these tumor suppressive functions of miR-382 to targeting and downregulating YB-1 (Xu et al., 2015). This microRNA is downregulated in NSCLC and exogenous miR382 expression inhibits NSCLC growth, migration and invasion via the suppression of SETD2 (Chen T. et al., 2017) and LMO3 (Chen et al., 2019). In breast cancer, inhibition of p90 RSK, a major kinase involved in YB-1 phosphorylation; see section "Post-Translational Modification in the Control of YB-1 Activity and Localization") using the small molecule LJI308 eradicated the population of breast CSCs and induced apoptosis in breast cancer cells (Davies et al., 2015). RSK is thought to have potential as a therapeutic target as it is involved in the proliferation of lung cancer (Poomakkoth et al., 2016). Furthermore, knockdown of WAVE3, a protein required for nuclear translocation of YB-1, prevented YB-1 mediated transcriptional activation NANOG, SOX2 and Oct4 in breast CSCs (Bledzka et al., 2017). WAVE3 expression was also correlated with that of YB-1 and more aggressive phenotypes of breast cancer (Bledzka et al., 2017).

\section{YB-1 Is Involved in Hypoxic Response}

The maintenance of CSCs is intertwined with the effects of hypoxia (Li and Rich, 2010). Supporting its role in thoracic CSC biology, hypoxia promotes an aggressive phenotype in MPM and upregulates Oct4, a marker of CSCs (Kim et al., 2018). Oct4 is also important in gefitinib-resistant lung CSCs and cisplatin-induced stemness in NSCLC has been linked to hypoxia-inducible factors (Kobayashi et al., 2016). Hypoxia occurs in most solid tumors and has been linked to CSC maintenance and behavior (Li and Rich, 2010; Bao et al., 2012), as well as disorganized tumor vascularization, EMT and metastasis (Muz et al., 2015). Factors such as HIF $1 \alpha$ drive hypoxia-mediated transcription, influencing cell immortalization, metastasis and vascularization (Semenza, 2014). YB-1 translationally regulates HIF1 $\alpha$ (El-Naggar et al., 2015) and acts as a transcriptional repressor for the HIF1 $\alpha$ inhibitor FOXO3a via competition for p300 during vascular development (Emerling et al., 2008; Chou et al., 2015). Under hypoxic conditions YB-1 translocates to the nucleus where it binds to hypoxia response elements within the $3^{\prime}$ enhancer of the EPO gene and blocks its expression (Rauen et al., 2016). Hypoxia plays an important role in driving malignant cellular behavior, including resistance to chemotherapy (Rohwer and Cramer, 2011). While YB-1-driven response to hypoxia may contribute toward chemoresistance, its activity as a transcription factor may also play a role in drug inefficacy.

\section{A Possible Role for YB-1 in Resistance to Platinum-Based Chemotherapy}

Although the role of YB-1 has not yet been studied in lung cancer or MPM, it has been shown to be involved in the 
chemoresistance of many cancers including that of platinumbased chemotherapies (To et al., 2010; Kang et al., 2013; Lasham et al., 2013; Shiota et al., 2014; Yamashita et al., 2017). Silencing YB-1 induces cisplatin sensitization in neuroblastoma (Wang H. et al., 2017), esophageal SCC (Xu and Hu, 2016), bladder cancer (Shiota et al., 2011) and melanoma (Schittek et al., 2007). Treatment with cisplatin also stimulates YB-1 production in bladder cancer (Shiota et al., 2010), while ovarian cancer cells with acquired cisplatin resistance show an increase in nuclear YB-1 expression (Yahata et al., 2002), suggesting that cancer cells may increase YB-1 production as a protective measure. The reasons why YB-1 may provide protection are still unclear. However, YB-1 does transcriptionally upregulate $L R P$, aka $M V P$ (Stein et al., 2005), the principal component of vaults in human cells. Vaults are highly conserved ribonucleoproteins which have been suggested to play a role in the resistance of cancer cells to cisplatin, among other chemotherapies, by sequestering drugs away from their intended targets (Wang W. et al., 2004; Lara et al., 2011). YB-1 knockdown in lung cancer cell lines resulted in LRP downregulation and nuclear staining of YB-1 correlated with LRP expression in 105 NSCLC samples, conferring significantly lower overall survival (Hyogotani et al., 2012). However, this study did not investigate the effect of this knockdown on the chemoresistance of any drug.

Y-box binding protein-1 has also been linked to MRP1 gene activation (Stein et al., 2001; Mantwill et al., 2006), an efflux ATP-binding cassette transporter which is thought to contribute toward multidrug resistance (Stefan and Wiese, 2019). High levels of LRP and MRP1 correlated with lower response to cisplatin chemotherapy, poorer progression free survival and overall survival in advanced NSCLC patients receiving cisplatin-based chemotherapy (Li J. et al., 2009; Li X.Q. et al., 2009). Treatment with cisplatin also induces heightened LRP expression in ADC and SCC cell lines (Xu et al., 2017a) and $L R P$ gene expression was significantly increased compared to control pleura samples in a study of MPM patients (Singhal et al., 2003). MDR1 gene (encoding P-glycoprotein 1), which is dependent on the nuclease and base excision repair enzyme APE1 expression, has also been implicated in YB-1-driven cisplatin resistance (Ohga et al., 1998; Chattopadhyay et al., 2008). However, the evidence supporting a clear role for P-glycoprotein 1 as an integral player in the chemoresistance of lung cancer and mesothelioma remains contentious, implying that other targets may be more important (Soini et al., 2001; Wangari-Talbot and Hopper-Borge, 2013).

\section{An Agent of DNA Repair in Response to Cisplatin and Oxidative Stress}

Y-box binding protein-1 may drive chemoresistance through the upregulation of the above targets and through driving a hypoxic response. However, some of its other functions may also contribute, such as its role as part of the DNA repair machinery. Oxidative stress and resulting chronic inflammation has long been implicated as a primary driver of cigarette smoking-related diseases, including lung cancer (Park et al., 2009; Sears, 2019). Altered DNA repair pathways have been implicated in the carcinogenesis of lung cancer in response to cigarette smoke-related DNA damage, particularly the NER and BER pathways (Sears, 2019). There is also a body of evidence supporting the suggestion that COPD leads to the development of lung cancer, or at least that the two are correlated (Sears, 2019). Chronic inflammation caused by asbestos-related oxidative stress is a major driver of MPM carcinogenesis (Benedetti et al., 2015; Chew and Toyokuni, 2015), implying that aberrations in DNA repair machinery in response to oxidization play a role in the progression of many thoracic cancers.

Y-box binding protein-1 has been suggested to be part of the DNA repair machinery as it binds to enzymes involved in BER, mismatch repair and DNA double-stranded break repair, previously reviewed (Alemasova and Lavrik, 2017). YB1 binds preferentially to cisplatin-damaged DNA complexed with PCNA, where it works to separate cisplatin-damaged DNA strands, recruit DNA repair proteins and displays weak endonucleolytic and exonucleolytic function (Ise et al., 1999; Gaudreault et al., 2004). PARP1 has also been shown to catalyze the poly(ADP-ribosyl)ation of YB-1 in the presence of DNA damage, further supporting a role for YB-1 in DNA repair (Alemasova et al., 2015).

Y-box binding protein-1 is also involved in NER and BER in response to oxidative stress. DNA damage-related stress stimulates YB-1 nuclear translocation (Cohen et al., 2010) (discussed further in section "Control of YB-1 Subcellular Localization") where it can bind to oxidized DNA lesions, structurally altering DNA to allow access to the damaged site while recruiting and scaffolding proteins involved in BER including PARP1, PARP2, NEIL1, and PCNA, among others (Dutta et al., 2015; Alemasova et al., 2016). In ssDNA, YB-1 suppresses NEIL1-mediated apurinic/apyrimidinic site cleavage, and it has been suggested that the role of YB-1 in DNA repair can prevent ssDNA breaks and induce oxidative nucleotide repair in double-stranded DNA (Dutta et al., 2015). YB-1 has also been linked to NER. Cross-talk between YB-1 and XPC (an important player in NER which has significance in lung cancer carcinogenesis and is affected by germline mutation in MPM), results in their assembly at DNA damage sites (Jin et al., 2014; Fomina et al., 2015; Betti et al., 2017; Sears, 2019).

Y-box binding protein-1 was found to be involved in mitigating cigarette smoke-induced guanine oxidization in lung fibroblasts and mice chronically exposed to cigarette smoke, and that lung samples of late-stage COPD patients exhibited significantly lower YB-1 levels compared to early mid stage patients or patients without COPD (Deslee et al., 2010). The role YB-1 plays in DNA repair (particularly from oxidization) and the fact that it is secreted under oxidizing conditions (see section "YB-1 is Secreted Into the Extracellular Space Under Cellular Stress") implies that YB-1 may promote the oxidation-related carcinogenesis of lung cancer and MPM. Cigarette-induced oxidative stress has additionally been suggested to induce the release of exosomes (Ryu et al., 2018), the sorting of which are also mediated in part by YB-1. 


\section{YB-1 and Exosomal RNA Sorting}

Extracellular vesicles such as exosomes are used by cells for intercellular communication to both their immediate and distant surroundings (Mashouri et al., 2019). Exosomes carry factors such as proteins, mRNA and miRNA to mediate processes including embryonic development, injury response and homeostasis (Mashouri et al., 2019). Exosomes also play versatile and key roles in cancer cell behavior and remodeling of the tumor microenvironment (Mashouri et al., 2019). A malignant role for exosomes in lung cancer is well documented, where exosomes can induce proliferation, angiogenesis, EMT changes and metastasis (Vanni et al., 2017; Zhou et al., 2017a; Ryu et al., 2018). Exposure to cigarette smoke is also thought to induce the release of extracellular vesicles, such as exosomes, which has been linked to the development of COPD and possibly the development of lung cancers (Ryu et al., 2018). Asbestos exposure also alters the exosomal cargo of lung epithelial cells in vitro and exposing non-malignant mesothelial cells to these exosomes induces gene expression changes related to EMT and other cancer related pathways (Munson et al., 2018). This indicates that exosomes may play an integral role in the carcinogenesis of mesothelioma. MPM cell lines also secrete higher levels of exosome-associated proteins linked to stress response and proliferation compared to their nonmalignant counterparts (Creaney et al., 2017). Supporting this, exosomes from MPM cells have a distinct oncogenic signature and stimulate the migration of fibroblasts and endothelial cells (Greening et al., 2016).

Y-box binding protein-1 is known to be involved in exosomal RNA-sorting, reviewed previously (Suresh et al., 2018), which may indicate it is involved in altering malignant exosomal expression profiles. Briefly, the presence of YB-1 in exosomes has been shown in both malignant and non-malignant cells alike where it helps to define the levels of several RNA species, including miRNA and tRNA (Shurtleff et al., 2017; Suresh et al., 2018). However, to our knowledge no study has investigated YB-1 in lung cancer and mesothelioma exosomal sorting. Future studies following this line may shed further light into the underlying mechanisms of exosomes and their role in thoracic cancer biology.

\section{A Role in Immune Evasion?}

Evidence in other tumor types suggests that the upregulation of YB-1 could drive immune evasion. For example, in doxorubicin-resistant hepatocellular carcinoma cells, YB-1 is overexpressed, which in turn transcriptionally upregulates the expression of PD-L1 and decreases the secretion of the chemokines IL1 $\beta$, IL10, and TGF $\beta$ in vitro (Tao et al., 2019). High YB-1 was also associated with resistance to cisplatin, gemcitabine, docetaxel, dasatinib and gefitinib in this study (Tao et al., 2019). This suggests that resistance to these drugs may also result in heightened PD-L1 and subsequent immunosuppression via $\mathrm{YB}-1$ upregulation, at least in hepatocellular carcinoma. In light of these results, investigating the potential of a similar role in thoracic cancers would be of great interest.

\section{YB-1 Regulation: A Complex Network of Transcriptional, Translational and Post-translational Control}

The wide-ranging roles of YB-1 in cell biology imply that its expression, localization and function must be tightly regulated in normal physiology. As YB-1 is frequently overexpressed in cancer, dysregulation of these controlling systems may play a role in malignant transformation. The expression and localization of YB-1 is controlled by a complex network of transcriptional, translational and autoregulatory signals discussed below.

\section{Transcriptional Control}

Several transcription factors have been found to promote YB1 transcription by binding to motifs in the YBX1 promoter. For example, YBX1 transcription has been shown to be promoted by GATA transcription factors, although recent evidence suggests the GATA family is less important for promoting YBX1 expression in ADC (Yokoyama et al., 2003; Murugesan et al., 2018). Possibly more important are the six E-boxes located in the promoter of YBX1 (Makino et al., 1996). The first is located at $48-53$ nucleotide residues away from the promoter, the second at $353-358$, the third at 458 463 , the fourth at 531-536, the fifth at 1147-1152, and the sixth at 1201-1206 (Makino et al., 1996). The E-box binding transcription factor Twist1 also stimulates $Y B X 1$ transcription, driving cell growth and EMT (Shiota et al., 2008; He et al., 2015; Figure 2). A recent meta-analysis of 572 NSCLC patients showed that high Twist1 expression significantly correlated with poorer patient prognosis, recurrence-free survival and lymph node or other metastasis ( $\mathrm{Li}$ et al., 2018). A small retrospective study of mesothelioma samples also showed that Twistl expression was significantly higher in sarcomatoid tumors (expressed in 7/7 of samples) compared to biphasic (6/10) and epithelioid tumors (7/17) (Iwanami et al., 2014). Although the percentage of samples positive for YB-1 was almost identical to that of Twist1 in this study (6/7 in sarcomatoid, 6/10 in biphasic and 7/17 in epithelioid), whether YB-1 and Twist1 were co-expressed in the same samples was not determined (Iwanami et al., 2014).

An E-box within the YB-1 promoter is also trans-activated by Myc and p73 to drive the transcription of YBX1 (Uramoto et al., 2002; Figure 2). The ability of Myc to transcriptionally activate $Y B X 1$ is interesting, not only as Myc drives malignant behavior and is often associated with poor prognosis in thoracic cancers (Jiang et al., 1992; Volm and Koomagi, 2000; Riquelme et al., 2014), but because YB-1 can itself initiate $M y c$ translation by acting as a specific internal ribosome entry segment-trans-activating factor (Cobbold et al., 2010). YB-1 was also shown to regulate $M y c$ at the transcriptional level in bladder cancer, with implications on aerobic glycolysis (Warburg effect) (Xu et al., 2017b). This feed forward loop was first described in multiple myeloma (Bommert et al., 2013), however, it is quite possible that a similar feed forward loop accounts for both YB-1 and Myc overexpression in thoracic cancers, driving malignant progression and aggressiveness. 


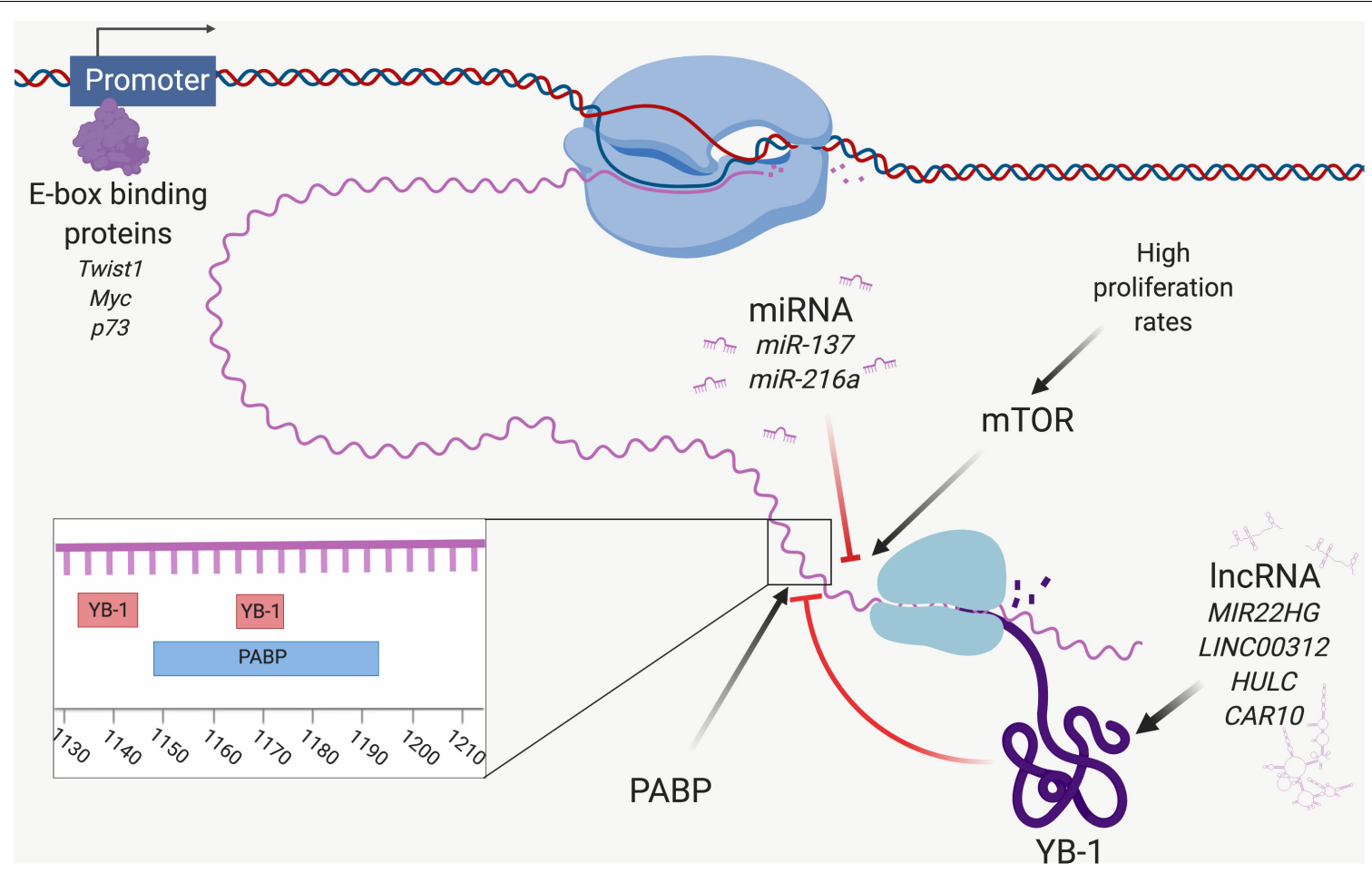

FIGURE 2 | Control of YB-1 expression. A network of factors controls YBX1 expression at the transcriptional and translational levels. The E-box binding proteins Twist1, Myc and p73 interact with the promoter of YBX1 and initiate transcription of YBX1 mRNA. YBX1 mRNA expression is downregulated by targeting miRNA, including miR-137 and miR-216a. YBX1 translation is stimulated by mTOR, which itself is influenced by proliferation rate. YB-1 protein function and expression are modulated by IncRNA, including MIR22HG and LINC00312. YB-1 is involved in an autoregulatory feedback loop and binds to YBX1 mRNA at two sites (nucleotides 1133-1145 and 1165-1172), inhibiting its own translation. PABP stimulates YBX1 translation by binding to a site located at 1149-1196, overlapping the second YB-1 binding site. Poly(A)-binding protein (PABP) and YB-1 compete for this site and hence regulate the level of YB-1 protein expression. Created with Biorender.com.

\section{Translational Regulation of YB-1}

Y-box binding protein-1 expression is also regulated at the translational level, most notably via signaling through the mTOR pathway (Figure 2), which regulates cell growth, motility, survival, transcription and protein synthesis via the integration of signals from hormone and growth factor stimulation, availability of nutrients, and stress (Zarogoulidis et al., 2014). mTOR signaling promotes the translation of $Y B X 1$ and increases the phosphorylation of RSK, a serine/threonine kinase which phosphorylates and thereby activates YB-1 (Mendoza et al., 2011; Lyabin et al., 2012). RSK has been implicated in lung cancer proliferation and has itself been suggested as a target with therapeutic significance (Poomakkoth et al., 2016).

The division rate of eukaryotic cells affects $Y B X 1$ translation via mTOR regulation. Slow dividing and serum-starved cell populations exhibit attenuated mTOR signaling, which in turn inhibits YBX1 translation (Lyabin et al., 2012). This pathway is frequently activated in lung cancer and antagonizing mTOR in such cells has proven to be a potential therapeutic avenue (Zarogoulidis et al., 2014). The PI3K/mTOR pathway is also highly activated in mesothelioma, but not in non-malignant mesothelial cells (Zhou et al., 2014) or adjacent tissue (Hoda et al., 2011), and phospho-mTOR was significantly associated with poorer overall survival in a cohort of 107 mesothelioma patients (Bitanihirwe et al., 2014). Dactolisib (BEZ235) treatment inhibited mesothelioma cell growth by targeting mTOR (Zhou et al., 2014) and similarly, treatment with the MTOR inhibitor temsirolimus stopped MPM cell proliferation and was synergistic with cisplatin treatment in vitro and in vivo (Hoda et al., 2011). It stands to reason that YB-1 overexpression is likely to be, at least in part, linked to the prominent role mTOR signaling plays in thoracic cancers.

\section{Autoregulation of YB-1 - An Unsolved Piece of the Puzzle}

Y-box binding protein-1 is controlled by an autoregulatory feedback loop in which YB-1 binds its own mRNA at two 8 nucleotide motifs at (nt) $1133-1145$ and nt 1165-1172, inhibiting translation prior to $40 \mathrm{~S}$ ribosomal subunit binding (Skabkina et al., 2005; Figure 2). PABP competes with YB-1 at one of these overlapping sites (nt 1149-1196), and stimulates YBX1 translation (Skabkina et al., 2003, 2005). Considering YB-1 overexpression is frequently observed in cancer, this feedback system may be dysregulated before or during malignant progression. It is possible that PABP upregulation could cause a bias for PABP translational activation of $Y B X 1$, although PABP itself is controlled by a similar autoregulatory loop (Ma et al., 2006). Nonetheless, recent expression and interactome analysis 


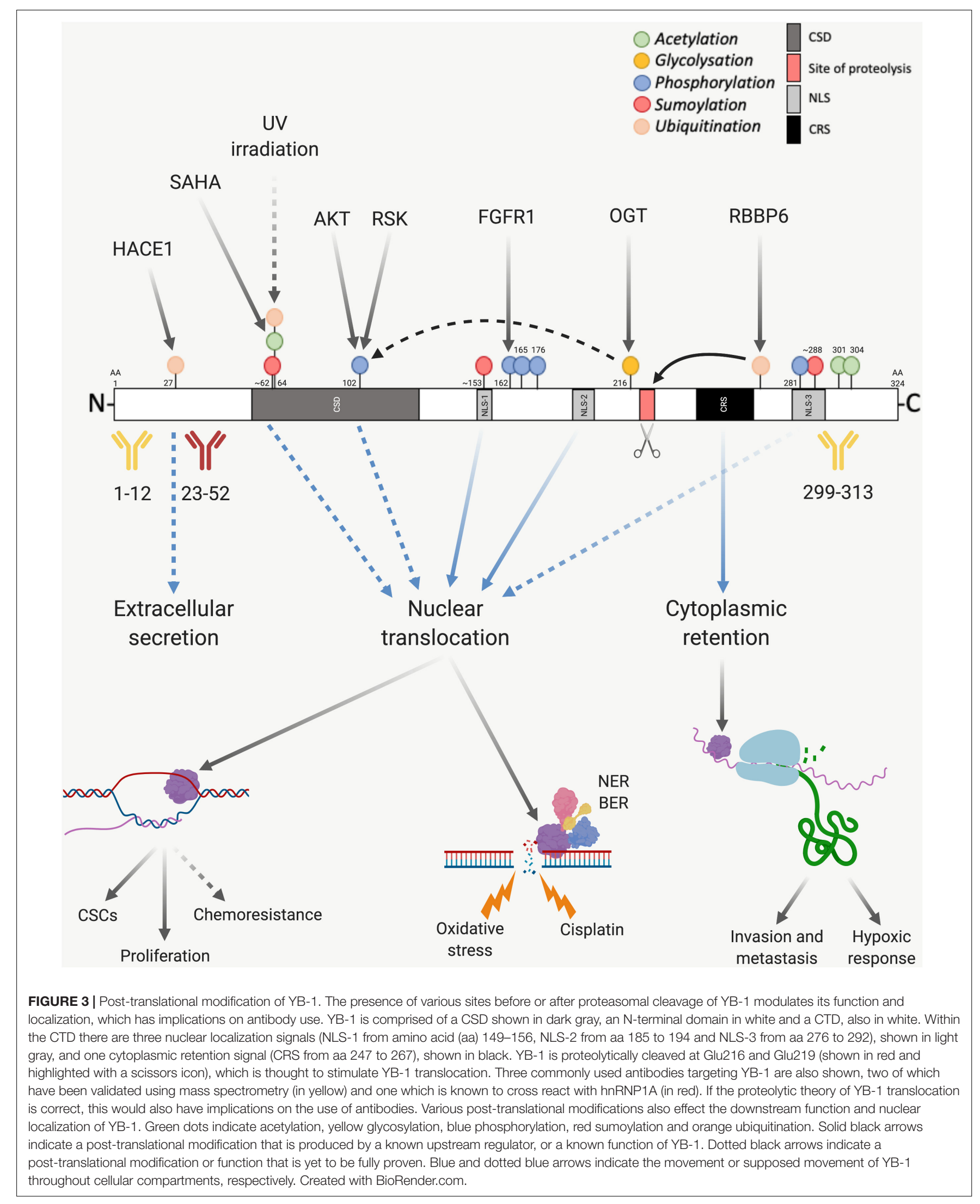


of YB-1 showed that PABP significantly correlated with YB-1 expression in ADC, implying it plays a central role in YB-1 upregulation and highlighting the need for further investigation into the PABP/YB-1 loop (Murugesan et al., 2018).

\section{Non-coding RNA Modulate YB-1 Expression}

Various families of ncRNAs also play a role in regulating YB-1 levels (Figure 2). One such family are miRNAs - a conserved class of short, ncRNAs that regulate gene expression by binding to and initiating RNA-induced silencing complex-mediated degradation of target mRNA (Jonas and Izaurralde, 2015). The inhibition of YBX1 by several miRNAs has been shown in other cancers, although to our knowledge such interactions have not been investigated in thoracic cancers. We recently demonstrated regulation of YBX1 by miR-137 in MPM cells, inhibiting growth, migration and invasion (Johnson et al., 2018). This miRNA is also known to act as a tumor suppressor in lung cancer by targeting SRC3 (Chen R. et al., 2017) and BMP7 (Yang et al., 2015). Another miRNA known to target $Y B X 1$ is miR-216a, which suppresses YB-1-mediated metastasis in pancreatic cancer (Lu et al., 2017). MiR-216a acts as an tumor suppressor in SCLC by targeting and downregulating the anti-apoptotic protein B-cell lymphoma 2 (Bcl-2) (Wang et al., 2018), although it is likely that these effects are also, in part, due to YBX1 downregulation.

The IncRNA DANCR has been implicated in reducing the levels of this miRNA through its complimentary miR-216a binding site, sequestering it away from miR-216a targets (Zhen et al., 2018). DANCR is associated with advanced tumor grade and poor prognosis in lung cancer and promotes ADC cell growth in vitro and in vivo (Zhen et al., 2018). Dysregulation of DANCR and subsequent lowering of miR-216a could represent one mechanism of YB-1 overexpression in thoracic cancer, representing an area which requires further investigation.

In addition to DANCR, other lncRNAs as well as transfer RNA-derived fragments can also play a role in regulating YB1 expression, reviewed previously (Suresh et al., 2018). One example is the IncRNA GAS5, which interacts with YB-1 protein and activates $Y B X 1$ translation, upregulating $\mathrm{p} 21$ and initiating G1 cell cycle arrest in stomach cancer (Liu et al., 2015). Interestingly, GAS5 knockdown did not affect YBX1 mRNA expression, something the authors attribute to possible interactions with other proteins (Liu et al., 2015). GAS5 is a known competing endogenous RNA for miR-137, which targets YBX1 in thoracic cancers (see above in this section) (Chen et al., 2018), so it is possible that this may contribute toward YBX1 translational upregulation. However, GAS5 knockdown does not affect YBX1 mRNA expression (Liu et al., 2015), as would be expected by an increase in miR-137 availability, so this does not fully explain this relationship. Further inquiry into the GAS5/YB-1 and possibly miR-137 relationship is required. GAS5 acts as a tumor suppressor and is lost in lung cancer and mesothelioma (Renganathan et al., 2014; Shi et al., 2015), which is consistent with findings in other cancer types (Gutschner et al., 2018). The apparent discrepancy between the tumor suppressive function of GAS5 and GAS5-mediated translational upregulation of the oncogene $Y B X 1$ remains unanswered and also warrants further study.

More recently, the lncRNA MIR22HG was shown to prevent proteasomal degradation of YB-1 in lung cancer cells, which might contribute to YB-1 overexpression (Su et al., 2018). LINC00312 also interacts with YB-1 driving invasion, migration and vascular mimicry of ADC cells, and LINC00312 is associated with metastasis in ADC patients (Peng et al., 2018). HULC is another lncRNA that binds to YB-1 in hepatocellular carcinoma cells, promoting Ser102 phosphorylation, the significance of which is further described in section "Post-Translational Modification in the Control of YB-1 Activity and Localization" (Li et al., 2017). HULC is overexpressed in NSCLC and can promote proliferation via SPHK1 upregulation, which is upstream of the PI3K/AKT pathway (Liu L. et al., 2018). This implies that HULC may also be involved in PI3Kmediated YB-1 activation. TP53TG1, yet another lncRNA, can also bind to YB-1 and inhibit its nuclear translocation, stopping it from transcriptionally activating its oncogenic targets (Diaz-Lagares et al., 2016). TP53TG1 is downregulated in NSCLC and its upregulation sensitized cisplatin resistant NSCLC cells to cisplatin (Xiao et al., 2018). This was attributed to the downregulation of miR-18 (Xiao et al., 2018), however, considering the likely role of YB-1 transcriptional regulation in cisplatin resistance (see section "A Possible Role for YB-1 in Resistance to Platinum-Based Chemotherapy"), it is possible that cytoplasmic retention of YB-1 also played a part in the cisplatin sensitivity seen here. Finally, CAR10 binds to and stabilizes YB1 , leading to the upregulation of EGFR in lung cancer and promoting proliferation (Wei et al., 2016). ncRNA therefore play an integral role in the expression and activity of YB-1, and dysregulation of these families is likely to contribute to YB-1 overexpression in cancer.

\section{Post-translational Modification in the Control of YB-1 Activity and Localization}

The activity of YB-1 is modulated through various posttranslational modifications (Figure 3), with phosphorylation being the best studied. Ser102 (located in the CSD of YB-1) is currently the most comprehensively studied phosphorylation site. This site is a target of AKT and RSK, making it downstream of both the MAPK/ERK and PI3K/AKT pathways (Sutherland et al., 2005; Stratford et al., 2008; Mendoza et al., 2011). Several additional phosphorylation sites on YB-1 have been identified including Tyr281, which is located within a NLS toward the C-terminal of YB-1 and correlates with the nuclear localization of either a YB-1 C-terminal fragment or full length YB-1 (van Roeyen et al., 2013) (refer to next section for more detail). Tyr162 on YB-1 is also reportedly phosphorylated by FGFR1 (Kasyapa et al., 2009), an important oncogenic driver in lung cancer (Jamal-Hanjani et al., 2017; Friedlaender et al., 2019) and mesothelioma (Schelch et al., 2014; Quispel-Janssen et al., 2018), however, to our knowledge the significance of this modification has not yet been established. Ser165 and Ser176 on YB-1 are also phosphorylated, each promoting distinct groups of nuclear factor- $\kappa \mathrm{B}$ target gene expression. This pathway is commonly 
dysregulated in thoracic cancers and drives cell survival, chemoand radiotherapy resistance (Chen et al., 2011; Nishikawa et al., 2014; Prabhu et al., 2015; Martin et al., 2017).

In the case of Ser102, it seems that phosphorylation is linked to the hexosamine biosynthetic pathway, in which OGT and O-linked $\mathrm{N}$-acetylglucosamine add or remove $\mathrm{N}$-acetylglucosamine groups to serine or threonine residues, respectively. OGT-mediated O-linked glycosylation of YB-1 at Thr216 aids in the phosphorylation of Ser102 and subsequent transcriptional activity of YB-1 in hepatocellular carcinoma (Liu et al., 2016; Figure 3).

Sumoylation, acetylation and ubiquitination are also prominent post-translational modifications that can contribute toward regulating YB-1 activity and localization. In addition, the nuclear localization of YB-1 has been linked to three NLS, mapped to amino acid residues 149-156 (NLS-1), residues 185-194 (NLS-2) and residues 276-292 (NLS-3) (van Roeyen et al., 2013).

Y-box binding protein-1 is sumoylated at three distinct sites in response to circadian rhythm in zebra fish cells, which has implications on its nuclear shuttling (Pagano et al., 2017). One of these sites is a canonical inverted sumoylation site (at amino acids 287-290 within NLS-3), while the other two are non-canonical sites (at 60-63 which is within the CSD and at 151-154, within NLS-1; Figure 3) (Pagano et al., 2017). Circadian disruption has been correlated with an increased risk of cancer development (Hansen, 2017; Liu W. et al., 2018) and many processes integral to tumorigenesis follow circadian rhythms (cell cycle regulation and DNA repair, for example). Although one study failed to find a link between night shift work and lung cancer among a cohort of female textile workers in Shanghai, China (Kwon et al., 2015), preclinical data indicates that disturbance of the circadian clock can promote lung tumor growth in vivo (Papagiannakopoulos et al., 2016). Modulation of YB-1 localization in response to light may represent one contributing factor in the observed correlation between circadian rhythm and cancer and warrants further investigation.

Acetylation of YB-1 has been reported to occur in lung cancer cells, however, the significance of this remains unclear. YB-1 was one of 542 proteins acetylated by the histone deacetylase inhibitor SAHA in SILAC experiments in a NSCLC cell line (Wu et al., 2015). Here, YB-1 was acetylated at Lys64 (Figure 3). Lys301/304 of YB-1 can also be acetylated and the amount of acetylated YB-1 is significantly increased in monocytes of hemodialysis patients (Ewert et al., 2018).

Ubiquitination may also play an important role in YB1 expression and subcellular localization. RBBP6 initiates proteasomal degradation of $\mathrm{YB}-1$ by binding to and ubiquitinating it within a 62-residue fragment of the YB-1 CTD (Chibi et al., 2008). The protein isoform of p63 $\Delta \mathrm{Np} 63 \alpha$ counteracts this by preventing proteolysis of full-length YB-1 and stimulating accumulation of poly-ubiquitinated YB-1 in the nucleus (di Martino et al., 2016), possibly supporting the role of proteolytic cleavage-dependent YB-1 nuclear shuttling (discussed further in section "Control of YB-1 Subcellular Localization"; Figures 3, 4). Further supporting this theory, UV irradiated DNA damage stimulates YB-1 ubiquitination at Lys64
(Boeing et al., 2016) (the same lysine residue that is acetylated, above in this section; Figure 3). Considering the DNA repair function of YB-1 and the aforementioned ubiquitination-driven proteasomal cleavage of $\mathrm{YB}-1$, this possibly induces a similar nuclear translocation of YB-1. This is further supported by results showing that YB-1 is shuttled to the nucleus upon UV irradiation (Koike et al., 1997).

Ubiquitination is also important in the secretion of YB-1 via the multi-vesicular body pathway. The E3 ligase activity of HACE1 polyubiquitinates YB-1 at K27, facilitating tumor susceptibility gene 101 binding, which initiates YB-1 secretion (Palicharla and Maddika, 2015). In summary, post-translational modification influences the levels, activity and localization of YB-1, which in turn impacts the downstream effects of YB-1.

\section{Control of YB-1 Subcellular Localization}

In non-malignant cells, YB-1 is primarily located in the cytoplasm and functions as a major component of free messenger ribonucleoprotein complexes, where it can inhibit or stimulate cap-dependent translation depending on the ratio of YB-1 to mRNA (Suresh et al., 2018). Under certain stresses such as cisplatin treatment (Yahata et al., 2002), hypoxia (Rauen et al., 2016), UV radiation (Koike et al., 1997), and hyperthermia (Stein et al., 2001), YB-1 translocates to the nucleus, however, the underlying mechanism of this remains unclear. As above, YB-1 has three NLS sites which have been mapped to amino acid residues 149-156, residues 185-194 and residues 276-292 (van Roeyen et al., 2013), which are recognized by transportin-1 (Mordovkina et al., 2016) and WAVE3 (Bledzka et al., 2017). In addition YB-1 also contains a CRS at residues 247-267 (Woolley et al., 2011; Figure 3). The locations of these sites are postulated to regulate YB-1 nuclear-cytoplasmic translocation.

One line of evidence suggests that nuclear translocation is preceded by a specific proteolytic cleavage by the $20 \mathrm{~S}$ proteasome of YB-1 at Glu216 and Glu219 under cellular stress (Sorokin et al., 2005; Kim et al., 2013; Figures 3, 4). This results in loss of a 105amino acid sequence from the C-terminus, including the CRS, and accumulation of the remaining $\mathrm{N}$-terminal fragment in the nucleus (Sorokin et al., 2005; Kim et al., 2013). The presence of an NLS in the CTD suggests that a C-terminal fragment may also be shuttled to the nucleus, presumably if the nearby CRS has been cleaved off (van Roeyen et al., 2013; Figures 3, 4). Supporting this, breast cancer cells preincubated with the proteasome inhibitor MG-132 before treatment with doxorubicin displayed reduced nuclear and enhanced cytoplasmic levels of YB-1 (visualized with a C-terminal-targeting antibody; Figure 3), compared to cells treated with doxorubicin alone (van Roeyen et al., 2013). However, this does not rule out whether full-length YB-1 translocation occurs by some other mechanism.

Countering the proteasomal theory is one study that suggests the YB-1 N-terminal fragment has been misidentified as another protein, hnRNP1A, and that only full-length YB-1 is found in the nucleus (Cohen et al., 2010). Full-length YB-1 nuclear translocation could be facilitated by its phosphorylation. For example, there is evidence showing that YB-1 is phosphorylated at Ser102 by the serine/threonine kinase AKT before being shuttled to the nucleus (Sutherland et al., 2005; Figures 3, 5). 


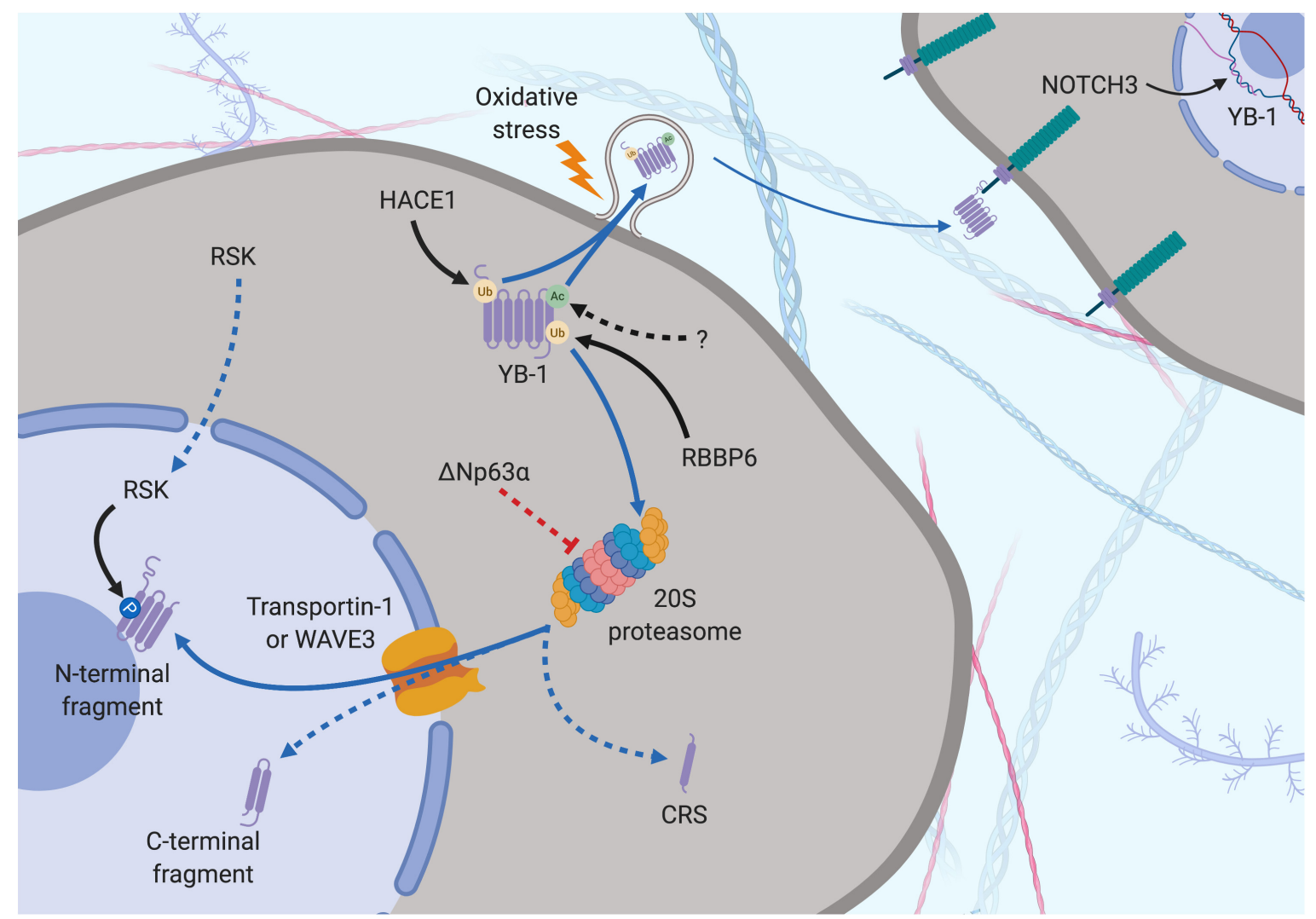

FIGURE 4 | Subcellular localization of YB-1 - the proteolytic theory of nuclear localization. YB-1 can be found in the nucleus, cytoplasm and extracellular space and its localization is mediated by various factors. Secretion can be preceded by Ubiquitination (orange dot) by HACE1 and acetylation (green dot) by a currently unknown protein. Oxidative stress stimulates stress-granule localization and eventual section of YB-1, where it can bind to the transmembrane protein Notch3 on other cells. YB-1 is cleaved by the proteasome prior to nuclear translocation. Ubiquitination by RBBP6 initiates YB-1 proteolytic cleavage. $\Delta$ Np63 $\alpha$ prevents full length proteolysis by partially inhibiting YB-1 degradation, resulting in the removal of the CRS. Transportin-1 or WAVE3 bind to NLS of YB-1 and translocate it to the nucleus. RSK can cross into the nucleus, phosphorylating nuclear YB-1 fragments. Solid black arrows indicate a post-translational modification that is produced by a described or known mechanism. Dotted black arrows indicate a post-translational modification whose significance is yet to be realized. Blue and dotted blue arrows indicate the movement or supposed movement of YB-1 throughout cellular compartments, respectively. Created with BioRender.com.

This may cause a conformational change which could block the CRS of YB-1, stimulating its nuclear shuttling. However, a recent study found that while ionizing radiation, EGF stimulation and overexpression of the KRAS G12V mutant induced Ser102 phosphorylation of YB-1 in both the nucleus and the cytoplasm, there was no increase in YB-1 expression in nuclear fractions (Tiwari et al., 2018). The authors attribute this to nuclear translocation of RSK, phosphorylating pre-existing nuclear YB1 - not the shuttling of YB-1 itself (Figure 4). It may be that the translocation of either YB-1, RSK or both is dependent on the type of cellular stress applied. As mentioned in section "PostTranslational Modification in the Control of YB-1 Activity and Localization," phosphorylation of Thr281 within the NLS 276292 of YB-1 also correlates with its nuclear translocation (van Roeyen et al., 2013), however, it is not yet clear whether this modification is actively involved in YB- 1 shuttling.

The localization of YB-1 also appears to be dependent on its ability to bind RNA and other proteins in the cytoplasm as YB-1 nuclear localization is hampered by higher cytoplasmic mRNA levels (Tanaka et al., 2018). This group also found that p53 (along with 4 other nucleocytoplasmic-shuttling proteins) binds to a YB-1 NLS and co-accumulates with YB-1 in the nucleus in response to actinomycin D treatment (Tanaka et al., 2016). This implies that YB-1 nuclear localization is a p53-mediated response to DNA stress. Another factor, C1QBP inhibits nuclear localization by binding to and blocking an NLS region (Matsumoto et al., 2018). C1QBP binding also moderately attenuated YB-1-mediated mRNA stabilization (Matsumoto et al., 2018). It is likely that the balance of this cytoplasmic interactome determines where YB-1 is localized under different conditions and that a disruption of this balance may lead to malignant progression.

\section{YB-1 Is Secreted Into the Extracellular Space Under Cellular Stress}

Stress-related secretion of factors found in the nucleus and cytoplasm have been found to be biologically relevant in thoracic cancer biology and may serve as potential non-invasive biomarkers. Secretion of the nuclear protein HMGB1 in response 


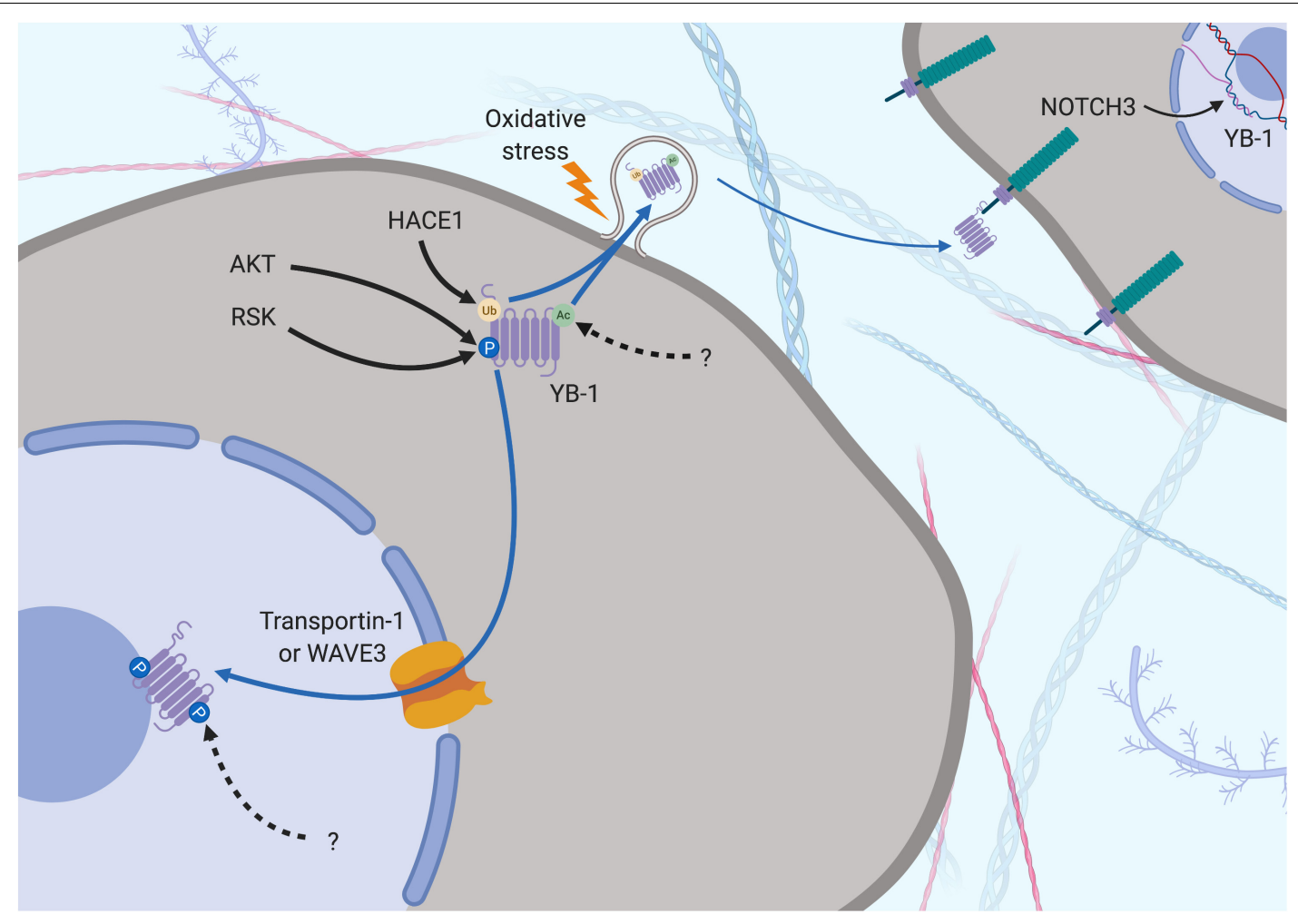

FIGURE 5 | Subcellular localization of YB-1 - the phosphorylation theory of nuclear localization. YB-1 can be found in the nucleus, cytoplasm and extracellular space and its localization is mediated by various factors. Secretion can be preceded by Ubiquitination (orange dot) by HACE1 and acetylation (green dot) by a currently unknown protein. Oxidative stress stimulates stress-granule localization and eventual section of YB-1, where it can bind to the transmembrane protein Notch3 on other cells. Phosphorylation is required before nuclear shuttling can take place. Ser102 is phosphorylated by upstream kinases, changing the configuration of YB-1 to block the CRS and allow nuclear shuttling via Transportin-1 or WAVE3. Phosphorylation of Tyr281 by a currently unknown upstream regulator may play a role here too. Solid black arrows indicate a post-translational modification that is produced by a described or known mechanism. Dotted black arrows indicate a post-translational modification whose significance is yet to be realized. Blue and dotted blue arrows indicate the movement or supposed movement of YB-1 throughout cellular compartments, respectively. Created with BioRender.com.

to asbestos-related necrosis in MPM cells, which acts as an alarmin to stimulate inflammation is one example (Yang et al., 2010). Serum HMGB1 has shown prognostic relevance as a possible biomarker in MPM (Tabata et al., 2013).

Y-box binding protein-1 is related on an evolutionary level to HMGB1 and is also secreted under certain cellular stresses. This was first evident in monocytes stimulated with bacterial lipopolysaccharide through an active, non-classical pathway and appears to require the same two lysine residues (Lys301/304) that are the site of acetylation in hemodialysis patients (Frye et al., 2009; Ewert et al., 2018; Figures 3-5). Secreted YB1 stimulated DNA synthesis, cell proliferation and migration of kidney cells (Frye et al., 2009). More pertinent to thoracic cancer, YB-1 is also secreted under oxidative stress. YB-1 translationally upregulates G3BP1 under oxidative stress and localizes to cytoplasmic stress granules where it is involved in pro-survival mRNA reprogramming (Somasekharan et al., 2015). G3BP1 also promotes the invasion and metastasis of sarcoma cells in vivo (Somasekharan et al., 2015). In support, YB-1 enrichment in stress granules is also linked to its secretion to the extracellular space under oxidizing conditions (Guarino et al., 2018; Figures 4, 5). Secretion of YB-1 resulted in depletion of cytoplasmic YB-1, leaving nuclear expression intact (presumably to allow for YB-1mediated DNA repair), while secreted YB-1 inhibited the growth of neighboring keratinocytes (Guarino et al., 2018).

Extracellular YB-1 acts as a ligand for Notch3, binding to epidermal growth factor-like repeats $17-24$ on Notch3 and subsequently promoting $Y B X 1$ translation in a feed-forward, autoregulatory fashion (Rauen et al., 2009; Raffetseder et al., 2011; Gera and Dighe, 2018; Figures 4, 5). Notch3 is frequently overexpressed in NSCLC where high levels correlate with poor prognosis, making it a candidate target for therapeutic intervention (Zong et al., 2016). Considering the prevalence of oxidative stress and Notch3 in thoracic cancers, the secretion of YB-1 may be biologically important, although more studies are required to fully understand this process.

\section{YB-1 IN THORACIC CANCERS: CLINICAL RELEVANCE}

\section{YB-1 as a Prognostic Biomarker}

There is evidence supporting the use of YB-1 as a prognostic biomarker in thoracic cancers, and subcellular localization is 
important in this regard. Analysis of TCGA data demonstrate that high levels of $Y B X 1 \mathrm{mRNA}$ correlate significantly with poor prognosis in NSCLC and MPM patients (Figures 1D,E). YB1 protein has been correlated with poor prognosis previously (Shibahara et al., 2001; Gessner et al., 2004), supported by a recent meta-analysis of six studies covering data on 692 NSCLC patients, where YB-1 was associated with worse overall survival, tumor stage and depth of invasion (Jiang et al., 2017). A study in MPM patients also supports the TCGA data (albeit tentatively due to the low number of patients in the cohort) (Iwanami et al., 2014). Here, YB-1 levels were shown to be higher in sarcomatoid MPM tumors, which confer the worst prognosis (Iwanami et al., 2014).

There has been some contention surrounding the use of particular YB-1 antibodies in prognostic studies across cancer types. One N-terminal targeting YB-1 antibody that binds to residues 23-52 has been used in prognostic studies in the past (Figure 3). However, this antibody has been shown to cross reacts with the ubiquitously expressed hnRNPA1 protein via mass spectrometry making it unsuitable for such application (Woolley et al., 2011). Antibodies targeting the extreme N-'terminus of YB-1 (residues 1-12) or residues 299-313 in the CTD (Cterminal) have been shown to be specific for YB-1, again by mass spectrometry (Woolley et al., 2011; Figure 3). However, the N-terminal antibody has been suggested as more suitable for prognostic applications as this region does not interact with other proteins, so this epitope may be more accessible (Woolley et al., 2011). Notably, all prognostic studies cited in this review utilize the C-terminal targeting antibody. Regardless, a universal standardization of one reliable antibody would significantly enhance the prognostic potential of YB-1 for diagnosis using traditional pathological tissue staining.

Secreted YB-1 may also have prognostic significance in cancer. One study of 44 breast cancer patients with bone metastases found that serum YB-1 was present in 50\% of patients and associated with extra-bone metastases and faster bone disease progression (Ferreira et al., 2017). There was a trend toward poorer overall survival in high-YB-1 patients, although a bigger cohort is needed to provide a more definitive answer (Ferreira et al., 2017). Another group found an YB-1/p18 in the plasma of patients with various diseases (including 32/38 lung cancers) but not in healthy controls via Western Blot using a monoclonal YB1 antibody (Tacke et al., 2014). This study found no prognostic significance of YB-1/p18 in any of the cancers tested, but they assert that YB-1/p18 may have diagnostic significance (Tacke et al., 2014). The small sample number in this study should be noted before the prognostic applicability of secreted YB-1 is ruled out. Investigating the prognostic significance of secreted fulllength or other fragments of YB-1, not just YB-1/p18, may also be of interest. The potential of $\mathrm{YB}-1$ as a circulating biomarker is intriguing as a non-invasive method of prognosis and diagnosis, although more studies with larger cohorts are required.

\section{Targeting YB-1: An Achievable Feat?}

In the past $\mathrm{YB}-1$ has been overlooked as a therapeutic target because of its role as a transcription and translation factor, which have been traditionally hard to target with small molecule inhibitors. However, recent advancements in the delivery of
RNA-based drugs has opened up new potential avenues of targeting oncoproteins such as YB-1 (Seton-Rogers, 2012; Afonin et al., 2014). We and others have shown that miRNA or siRNA can be used to target $Y B X 1$ in thoracic cancer cells in preclinical studies (Xu et al., 2015; Johnson et al., 2018). The delivery of miRNA mimics in the clinic is now thought to be a viable anti-cancer strategy. For example, MRX34 (a liposomal miR-34a mimic) showed evidence of efficacy and safety in a phase I trial in patients with various solid tumors including 1 NSCLC patient (Beg et al., 2017). More pertinently, a phase 1 clinical trial delivering miR-16-based mimics using bacterial minicells (EnGeneIC Dream Vectors) in mesothelioma and advanced NSCLC patients demonstrated the safety and efficacy of miRNA-based therapy (van Zandwijk et al., 2017), evidencing the potential for miRNA replacement therapy in patients with thoracic cancer.

There are a number of systems which pose as attractive options to deliver RNA-based drug payloads in thoracic cancer such as lipid, RNA, inorganic and polymer-based nanoparticles, all with their respective advantages and drawbacks (Shu et al., 2014). The delivery of siRNA or miRNA using nanoparticles in lung cancers, and to a lesser extent MPM, has been achieved in vitro and in vivo, evidencing the potential of these delivery systems (Lee et al., 2016). The in vivo transport of siRNA to large cell lung carcinoma tumors using lipoprotein nanoparticles (Tagalakis et al., 2018) and ADC tumors using polyethylene glycol nanoparticles (Wen et al., 2017) has demonstrated the applicability of nanoparticle delivery systems for targeted therapy. However, these studies treated subcutaneously grown tumors, which do not reflect the orthotopic context of thoracic cancer and the problems with delivery that come with it. Recently though, an siRNA targeting anti-EZH2 was successfully delivered to orthotopically grown NSCLC tumors in mice using modified polyethyleneimine nanoparticles (Yuan et al., 2017), and delivery and retention of amiloride-sensitive epithelial sodium channelspecific siRNA into the lungs of normal mice was achieved (Tagalakis et al., 2018). The successful delivery of miR-215-5p miRNA mimics complexed in an atelocollagen vehicle was also recently achieved in an orthotopic MPM mouse model, which significantly suppressed tumor growth (Singh et al., 2019). The advances in RNA-based drug delivery in preclinical and clinical studies mean that siRNA or miRNA delivery is an appealing YB1 targeting strategy in thoracic cancers. However, other potential strategies may also be of interest, although these are yet to be investigated in humans.

Inhibiting YB-1 activation may be one such viable targeting strategy. Fisetin $\left(3,7,3^{\prime}, 4^{\prime}\right.$-tetrahydroxy flavone) is a flavanol that binds to the CSD of YB-1, inhibiting its phosphorylation at Ser102 and blocking EMT in prostate cancer cells in vitro (Khan et al., 2014). Targeting YB-1 using fisetin also attenuated the growth of melanoma cells in vitro and in vivo (Sechi et al., 2018). Fisetin was also found to inhibit mTOR and PI3K/Akt signaling in NSCLC cells, both of which are important in both thoracic cancer biology and YB-1 regulation (see section “Translational Regulation of YB-1") (Khan et al., 2012). Another possible method for targeting YB-1 was demonstrated by using an interference cell permeable peptide that prevented YB-1 Ser102 
phosphorylation. This led to an inhibition of EGFR expression and reduced growth of prostate and breast cancer cells, but not of non-malignant mammary epithelial cells (Law et al., 2010). Upstream inhibitors such as those targeting mTOR may also be an option (Hoda et al., 2011; Zhou et al., 2014), but would not be specific. A recent study showed that 2,4-dihydroxy-5-pyrimidinyl imidothiocarbomate antagonizes YB-1, inhibits YB-1 nuclear translocation and increases doxorubicin accumulation in breast cancer cells (Gunasekaran et al., 2018).

The use of oncolytic viruses that require YB-1 for replication is another potential therapeutic approach. XVir-N-31-mediated lysis of brain CSCs and virus production was significantly reduced in non-malignant astrocyte cells that expressed significantly less YB-1 compared to CSC cells (Mantwill et al., 2013). XVir-N-31 also repressed the growth of bladder cancer cells with strong YB-1 expression in vitro and intratumor delivery significantly repressed tumor volume in vivo (Lichtenegger et al., 2018). Consequently, virotherapy may prove to be an interesting avenue for targeting YB-1 overexpressing lung cancer and MPM.

Preclinical evidence in other tumors suggests that targeting YB-1 could also benefit immunotherapy in some cases. YB1 knockdown increased the efficacy of IFN- $\alpha$ in renal cell carcinoma cells in vitro and in vivo (Takeuchi et al., 2013). IFN- $\alpha$ in combination with cisplatin provided a partial response in five out of ten patients in an open-label non-comparative phase II study of NSCLC patients (Chao et al., 1995). A phase II randomized study in SCLC patients with limited disease also showed a survival benefit of IFN- $\alpha$ in combination with a chemotherapy regime of carboplatin, ifosfamide and etoposide (Zarogoulidis et al., 2013). Based on these results, further investigating whether targeting YB-1 could increase the modest efficacy of IFN- $\alpha$ in thoracic cancer is warranted.

The use of YB-1 as a tumor-associated antigen in therapeutic vaccination has also shown promise in other cancers. YB-1 was identified as a tumor-associated antigen in neuroblastoma by serological expression of cDNA expression libraries (Zheng et al., 2009). In the context of regulatory T-cell depletion, YB-1 immunization enhanced $\mathrm{CD}^{+}$response against neuroblastoma cells and conferred significantly higher mouse survival compared to control groups (Zheng et al., 2012). Adoptive T-cell therapy from immunized mice into neuroblastoma tumor-bearing mice also conferred a significant survival benefit and reduced tumor growth (Zheng et al., 2012). Again, further study in the context of thoracic cancer is warranted.

It must be noted that as with all current targeted therapies, it is likely that a YB-1-based approach to thoracic cancer management would benefit only a sub-population of patients. YB-1 overexpression, rather than mutation, would probably be the best predictive marker as mutations of $\mathrm{YB}-1$ are very rare

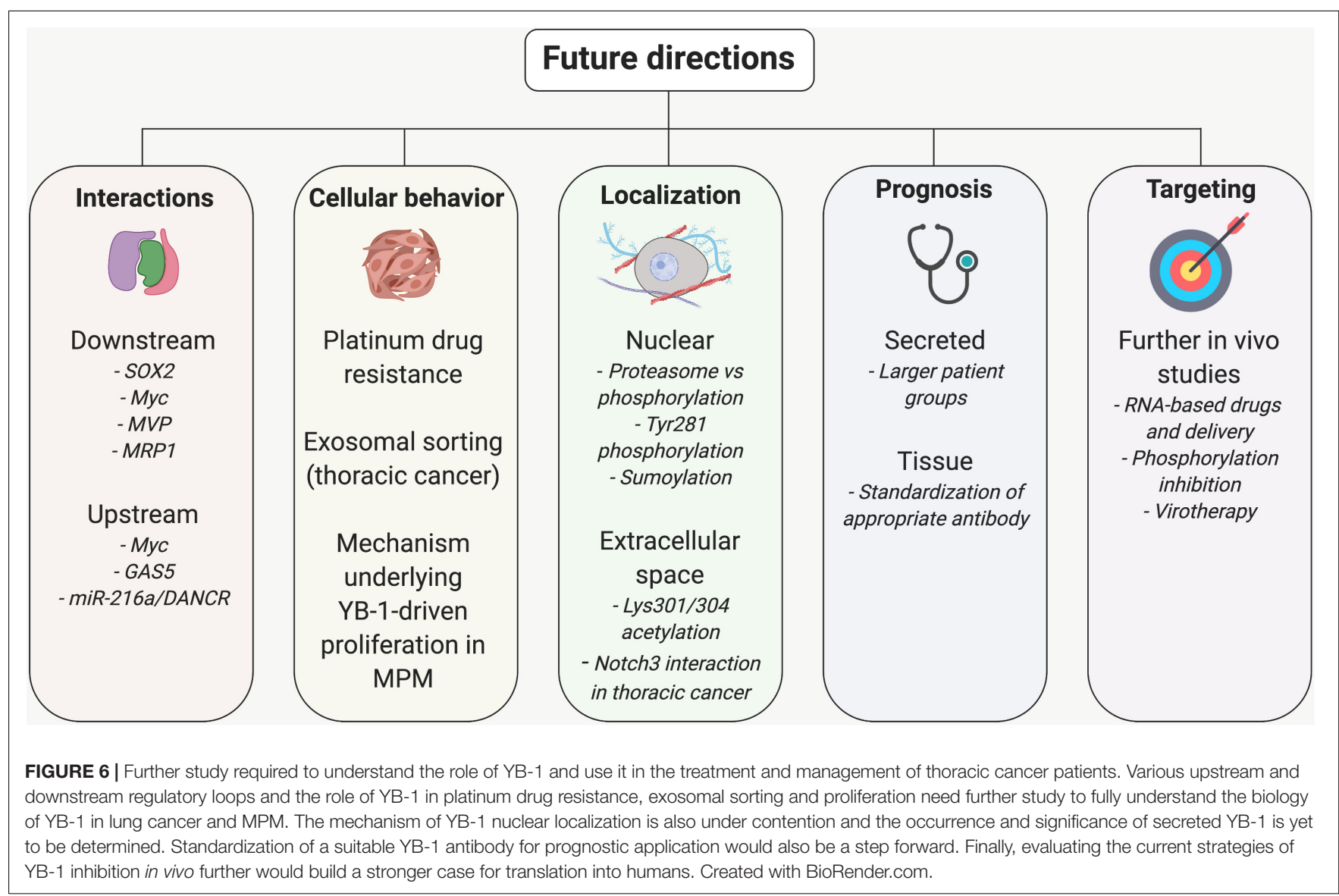


(Cerami et al., 2012; Gao et al., 2013). TCGA data (Figure 1) suggests that $\sim 10 \%$ of thoracic cancer patients would benefit, making it comparable to ALK inhibitors in ADC according to these datasets.

\section{FUTURE DIRECTIONS AND AREAS REQUIRING FURTHER STUDY}

Throughout this review we have highlighted some avenues for potential future research that currently require further consideration, summarized briefly below. The YB-1/SOX2 axis needs to be further investigated in lung cancer, particularly in SCC and SCLC where the development of new therapeutic strategies is most urgent. The feed-forward loop of YB-1 and $\mathrm{Myc}$ also requires further investigation in the context of thoracic cancer. The roles of certain ncRNA in the dysregulation of YB-1 are also still unclear, namely the relationship between GAS5, miR-137 and YB-1 and the potential DANCR/miR-216a/YB-1 loop. Also, the apparent tumor suppressor function of GAS5 does not fit with its role in promoting YB-1 translation, which is another area requiring further attention.

While there is strong evidence supporting YB-1-driven resistance to platinum chemotherapy in other cancers, a study looking at the effect of YB-1 knockdown on cisplatin or other platinum drug sensitivity in lung cancer or MPM cells is still required. Also, while YB-1 has been shown to upregulate LRP and MRP1, the effect of these interactions on cisplatin resistance are yet to be determined. Determining the involvement of YB1 in thoracic cancer exosomes would also be of interest. And while the mechanism underlying YB-1-driven growth in lung cancer has been studied well, similar studies in MPM cells are yet to be conducted.

Perhaps the most contentious area warranting further study relates to the regulation of YB-1 localization. Determining whether the proteolytic theory, phosphorylation theory or both is correct remains an important determination to be made. While these theories represent the most studied lines of evidence covering YB-1 nuclear localization, other posttranslational modifications could also play a role and deserve further attention, including the phosphorylation of Tyr281. However, what upstream regulator phosphorylates YB-1 here and whether this post-translational modification actually plays an important role is not yet known. Determining whether sumoylation and circadian-related YB-1 translocation occurs and is important in lung cancer and MPM patients would also be of interest.

The secretion of YB-1 into the extracellular space in response to oxidative stress has been reported in other cell types but is yet to be studied in thoracic cancers. If secretion does occur in these contexts, it would be interesting to determine whether acetylation of Lys301/304 is required, as in immune cells. Evaluating the potential interaction between secreted YB-1 and Notch3 here would also be interesting. It is also possible that secreted YB-1 could be used as a biomarker down the line, however, studies with larger patient numbers are required to determine this. Regardless, the evidence supports utilizing YB-1 as a prognostic tissue biomarker, however, universal standardization of an appropriate YB-1 antibody is would be favorable.

Finally, YB-1 remains an interesting target in thoracic cancer, but further in vivo studies delivering YB-1-targeting drugs need to be done before translation into humans can occur. This section is summarized in Figure 6.

\section{CONCLUSION}

In summary, this review covers recent advances in the understanding of YB-1 in cancer biology with a focus on thoracic cancers. YB-1 plays an important role in the malignant behaviors of lung cancer and MPM including proliferation, invasion and metastasis. It also has been shown to be involved in the maintenance and behavioral regulation of CSCs. The demonstrated prognostic significance of YB-1 and developments in the delivery of RNAbased drugs mean that utilizing this multifunctional oncoprotein in the management of thoracic cancer may soon become a reality.

\section{AUTHOR CONTRIBUTIONS}

This review was drafted by TJ and critically revised by KS, SM, $\mathrm{AB}$, and GR.

\section{FUNDING}

TJ was supported by a Ph.D. Scholarship from the Asbestos Diseases Foundation of Australia and a Top-Up Ph.D. Scholarship from the Sydney Catalyst Translational Cancer Research Centre, Australia (scholarship ID 470119385). KD was supported by a Firnberg Program Grant from the FWF (Austrian Science Fund, project number T 1062 Firnberg Program). AB was supported by a NBCF Investigator Initiated Research Scheme (IIRS-18-103). We would also like to thank the Asbestos Diseases Research Institute and Sydney Catalyst for funding the publication costs associated with this review.

\section{ACKNOWLEDGMENTS}

We would like to acknowledge the contributions of and thank Dr. Yuen Yee Cheng and Prof. Ken Takahashi from the Asbestos Diseases Research Institute, Prof. Fiona Blyth from the University of Sydney and Prof. Monica Robotin from the University of Notre Dame for their helpful suggestions and additions to this work. 


\section{REFERENCES}

Afonin, K. A., Viard, M., Kagiampakis, I., Case, C. L., Dobrovolskaia, M. A., Hofmann, J., et al. (2014). Triggering of RNA Interference with RNA-RNA, RNA-DNA, and DNA-RNA Nanoparticles. ACS Nano 9, 251-259. doi: 10. 1021/nn504508s

Alemasova, E., and Lavrik, O. (2017). At the interface of three nucleic acids: the role of RNA-binding proteins and poly (ADP-ribose) in DNA repair. Acta Naturae 9, 4-16. doi: 10.32607/20758251-2017-9-2-4-16

Alemasova, E. E., Moor, N. A., Naumenko, K. N., Kutuzov, M. M., Sukhanova, M. V., Pestryakov, P. E., et al. (2016). Y-box-binding protein 1 as a noncanonical factor of base excision repair. Biochim. Biophys. Acta Proteins Proteom. 1864, 1631-1640. doi: 10.1016/j.bbapap.2016.08.012

Alemasova, E. E., Pestryakov, P. E., Sukhanova, M. V., Kretov, D. A., Moor, N. A., Curmi, P. A., et al. (2015). Poly (ADP-ribosyl) ation as a new posttranslational modification of YB-1. Biochimie 119, 36-44. doi: 10.1016/j.biochi.2015. 10.008

Astanehe, A., Finkbeiner, M., Hojabrpour, P., To, K., Fotovati, A., Shadeo, A., et al. (2009). The transcriptional induction of PIK3CA in tumor cells is dependent on the oncoprotein Y-box binding protein-1. Oncogene 28:2406. doi: 10.1038/ onc. 2009.81

Bao, B., Azmi, A. S., Ali, S., Ahmad, A., Li, Y., Banerjee, S., et al. (2012). The biological kinship of hypoxia with CSC and EMT and their relationship with deregulated expression of miRNAs and tumor aggressiveness. Biochim. Biophys. Acta Rev. Cancer 1826, 272-296. doi: 10.1016/j.bbcan.2012.04.008

Beg, M. S., Brenner, A. J., Sachdev, J., Borad, M., Kang, Y.-K., Stoudemire, J., et al. (2017). Phase I study of MRX34, a liposomal miR-34a mimic, administered twice weekly in patients with advanced solid tumors. Invest. New Drugs 35, 180-188. doi: 10.1007/s10637-016-0407-y

Benedetti, S., Nuvoli, B., Catalani, S., and Galati, R. (2015). Reactive oxygen species a double-edged sword for mesothelioma. Oncotarget 6:16848.

Betti, M., Casalone, E., Ferrante, D., Aspesi, A., Morleo, G., Biasi, A., et al. (2017). Germline mutations in DNA repair genes predispose asbestos-exposed patients to malignant pleural mesothelioma. Cancer Lett. 405, 38-45. doi: 10.1016/j. canlet.2017.06.028

Bitanihirwe, B. K., Meerang, M., Friess, M., Soltermann, A., Frischknecht, L., Thies, S., et al. (2014). PI3K/mTOR signaling in mesothelioma patients treated with induction chemotherapy followed by extrapleural pneumonectomy. J. Thorac. Oncol. 9, 239-247. doi: 10.1097/JTO.0000000000000055

Bledzka, K., Schiemann, B., Schiemann, W. P., Fox, P., Plow, E. F., and SosseyAlaoui, K. (2017). The WAVE3-YB1 interaction regulates cancer stem cells activity in breast cancer. Oncotarget 8:104072. doi: 10.18632/oncotarget.22009

Boeing, S., Williamson, L., Encheva, V., Gori, I., Saunders, R. E., Instrell, R., et al. (2016). Multiomic analysis of the UV-induced DNA damage response. Cell Rep. 15, 1597-1610. doi: 10.1016/j.celrep.2016.04.047

Bommert, K., Effenberger, M., Leich, E., Küspert, M., Murphy, D., Langer, C., et al. (2013). The feed-forward loop between YB-1 and MYC is essential for multiple myeloma cell survival. Leukemia 27, 441-450. doi: 10.1038/leu.2012.185

Brabletz, T. (2012). To differentiate or not-routes towards metastasis. Nat. Rev. Cancer 12, 425-436. doi: 10.1038/nrc3265

Bradbury, P., Sivajohanathan, D., Chan, A., Kulkarni, S., Ung, Y., and Ellis, P. M. (2017). Postoperative adjuvant systemic therapy in completely resected nonsmall-cell lung cancer: a systematic review. Clin. Lung Cancer 18, 259.e8-273.e8. doi: 10.1016/j.cllc.2016.07.002

Brosseau, S., Assoun, S., Naltet, C., Steinmetz, C., Gounant, V., and Zalcman, G. (2017). A review of bevacizumab in the treatment of malignant pleural mesothelioma. Future Oncol. 13, 2537-2546. doi: 10.2217/fon-2017-0307

Bueno, R., Stawiski, E. W., Goldstein, L. D., Durinck, S., De Rienzo, A., Modrusan, Z., et al. (2015). Comprehensive genomic analysis of malignant pleural mesothelioma identifies recurrent mutations, gene fusions and splicing alterations. Nat. Genet. 47, 407-416. doi: 10.1038/ng.3520

Byers, L. A., and Rudin, C. M. (2015). Small cell lung cancer: where do we go from here? Cancer 121, 664-672. doi: 10.1002/cncr.29098

Cerami, E., Gao, J., Dogrusoz, U., Gross, B. E., Sumer, S. O., Aksoy, B. A., et al. (2012). The cBio cancer genomics portal: an open platform for exploring multidimensional cancer genomics data. Cancer Discov. 2, 401-404. doi: 10. 1158/2159-8290.CD-12-0095
Chao, H.-M., Huang, H.-X., Chang, P.-H., Tseng, K.-C., Miyajima, A., and Chern, E. (2017). Y-box binding protein-1 promotes hepatocellular carcinomainitiating cell progression and tumorigenesis via $\mathrm{Wnt} / \beta$-catenin pathway. Oncotarget 8:2604. doi: 10.18632/oncotarget.13733

Chao, T., Hwang, W., Yang, M., Chang, J.-Y., Wang, C., Hseuh, E., et al. (1995). Combination chemoimmunotherapy with interferon-alpha and cisplatin in patients with advanced non-small cell lung cancer. Zhonghua yi xue za zhi 56, 232-238.

Chattopadhyay, R., Das, S., Maiti, A. K., Boldogh, I., Xie, J., Hazra, T. K., et al. (2008). Regulatory role of human AP-endonuclease (APE1/Ref-1) in YB-1mediated activation of the multidrug resistance gene MDR1. Mol. Cell. Biol. 28, 7066-7080. doi: 10.1128/MCB.00244-08

Chen, D., Zhang, Y., Lin, Y., Shen, F., Zhang, Z., and Zhou, J. (2019). MicroRNA382 inhibits cancer cell growth and metastasis in NSCLC via targeting LMO3. Exp. Ther. Med. 17, 2417-2424. doi: 10.3892/etm.2019.7271

Chen, F., Zhang, L., Wang, E., Zhang, C., and Li, X. (2018). LncRNA GAS5 regulates ischemic stroke as a competing endogenous RNA for miR-137 to regulate the Notch1 signaling pathway. Biochem. Biophys. Res. Commun. 496, 184-190. doi: 10.1016/j.bbrc.2018.01.022

Chen, R., Zhang, Y., Zhang, C., Wu, H., and Yang, S. (2017). miR-137 inhibits the proliferation of human non-small cell lung cancer cells by targeting SRC3. Oncol. Lett. 13, 3905-3911. doi: 10.3892/ol.2017.5904

Chen, T., Ren, H., Thakur, A., Yang, T., Li, Y., Zhang, S., et al. (2017). miR-382 inhibits tumor progression by targeting SETD8 in non-small cell lung cancer. Biomed. Pharmacother. 86, 248-253. doi: 10.1016/j.biopha.2016.12.007

Chen, W., Li, Z., Bai, L., and Lin, Y. (2011). NF-kappaB in lung cancer, a carcinogenesis mediator and a prevention and therapy target. Front. Biosci. 16:1172-1185.

Chew, S. H., and Toyokuni, S. (2015). Malignant mesothelioma as an oxidative stress-induced cancer: an update. Free Radic. Biol. Med. 86, 166-178. doi: 10. 1016/j.freeradbiomed.2015.05.002

Chibi, M., Meyer, M., Skepu, A., Rees, D. J. G., Moolman-Smook, J. C., and Pugh, D. J. (2008). RBBP6 interacts with multifunctional protein YB-1 through its RING finger domain, leading to ubiquitination and proteosomal degradation of YB-1. J. Mol. Biol. 384, 908-916. doi: 10.1016/j.jmb.2008.09.060

Chiou, S.-H., Wang, M.-L., Chou, Y.-T., Chen, C.-J., Hong, C.-F., Hsieh, W.-J., et al. (2010). Coexpression of Oct4 and Nanog enhances malignancy in lung adenocarcinoma by inducing cancer stem cell-like properties and epithelialmesenchymal transdifferentiation. Cancer Res. 70, 10433-10444. doi: 10.1158/ 0008-5472.can-10-2638

Chou, C.-C., Chuang, H.-C., Salunke, S. B., Kulp, S. K., and Chen, C.-S. (2015) A novel HIF-1 $\alpha$-integrin-linked kinase regulatory loop that facilitates hypoxiainduced HIF- $1 \alpha$ expression and epithelial-mesenchymal transition in cancer cells. Oncotarget 6:8271.

Ciardiello, F., De Vita, F., Orditura, M., and Tortora, G. (2004). The role of EGFR inhibitors in nonsmall cell lung cancer. Curr. Opin. Oncol. 16, 130-135. doi: 10.1097/00001622-200403000-00008

Cobbold, L., Wilson, L., Sawicka, K., King, H., Kondrashov, A., Spriggs, K., et al. (2010). Upregulated c-myc expression in multiple myeloma by internal ribosome entry results from increased interactions with and expression of PTB-1 and YB-1. Oncogene 29:2884. doi: 10.1038/onc.2010.31

Cohen, S., Ma, W., Valova, V., Algie, M., Harfoot, R., Woolley, A., et al. (2010). Genotoxic stress-induced nuclear localization of oncoprotein YB-1 in the absence of proteolytic processing. Oncogene 29, 403-410. doi: 10.1038/onc. 2009.321

Creaney, J., Dick, I. M., Leon, J. S., and Robinson, B. W. (2017). A proteomic analysis of the malignant mesothelioma secretome using iTRAQ. Cancer Genomics Proteom. 14, 103-117.

Dalerba, P., and Clarke, M. F. (2007). Cancer stem cells and tumor metastasis: first steps into uncharted territory. Cell Stem Cell 1, 241-242. doi: 10.1016/j.stem. 2007.08.012

Davies, A. H., Reipas, K., Hu, K., Berns, R., Firmino, N., Stratford, A. L., et al. (2015). Inhibition of RSK with the novel small-molecule inhibitor LJI308 overcomes chemoresistance by eliminating cancer stem cells. Oncotarget 6:20570.

Deslee, G., Adair-Kirk, T. L., Betsuyaku, T., Woods, J. C., Moore, C. H., Gierada, D. S., et al. (2010). Cigarette smoke induces nucleic-acid oxidation in lung 
fibroblasts. Am. J. Respir. Cell Mol. Biol. 43, 576-584. doi: 10.1165/rcmb.20090221OC

Destro, A., Ceresoli, G., Falleni, M., Zucali, P., Morenghi, E., Bianchi, P., et al. (2006). EGFR overexpression in malignant pleural mesothelioma: an immunohistochemical and molecular study with clinico-pathological correlations. Lung Cancer 51, 207-215.

di Martino, O., Troiano, A., Guarino, A. M., Pollice, A., Vivo, M., La Mantia, G., et al. (2016). $\Delta$ Np63 $\alpha$ controls YB-1 protein stability: evidence on YB1 as a new player in keratinocyte differentiation. Genes Cells 21, 648-660. doi: $10.1111 /$ gtc. 12373

Diaz-Lagares, A., Crujeiras, A. B., Lopez-Serra, P., Soler, M., Setien, F., Goyal, A., et al. (2016). Epigenetic inactivation of the p53-induced long noncoding RNA TP53 target 1 in human cancer. Proc. Natl. Acad. Sci. U.S.A. 113, E7535-E7544.

Didier, D. K., Schiffenbauer, J., Woulfe, S. L., Zacheis, M., and Schwartz, B. D. (1988). Characterization of the cDNA encoding a protein binding to the major histocompatibility complex class II Y box. Proc. Natl. Acad. Sci. U.S.A. 85, 7322-7326. doi: 10.1073/pnas.85.19.7322

Dutta, A., Yang, C., Sengupta, S., Mitra, S., and Hegde, M. L. (2015). New paradigms in the repair of oxidative damage in human genome: mechanisms ensuring repair of mutagenic base lesions during replication and involvement of accessory proteins. Cell. Mol. Life Sci. 72, 1679-1698. doi: 10.1007/s00018014-1820-z

El-Naggar, A. M., Veinotte, C. J., Cheng, H., Grunewald, T. G., Negri, G. L., Somasekharan, S. P., et al. (2015). Translational activation of HIFl $\alpha$ by YB1 promotes sarcoma metastasis. Cancer Cell 27, 682-697. doi: 10.1016/j.ccell. 2015.04.003

Emerling, B. M., Weinberg, F., Liu, J.-L., Mak, T. W., and Chandel, N. S. (2008) PTEN regulates p300-dependent hypoxia-inducible factor 1 transcriptional activity through Forkhead transcription factor 3a (FOXO3a). Proc. Natl. Acad. Sci. U.S.A. 105, 2622-2627. doi: 10.1073/pnas.0706790105

Evdokimova, V., Tognon, C., Ng, T., Ruzanov, P., Melnyk, N., Fink, D., et al. (2009a). Translational activation of snaill and other developmentally regulated transcription factors by YB-1 promotes an epithelial-mesenchymal transition. Cancer Cell 15, 402-415. doi: 10.1016/j.ccr.2009.03.017

Evdokimova, V., Tognon, C., Ng, T., and Sorensen, P. H. (2009b). Reduced proliferation and enhanced migration: two sides of the same coin? Molecular mechanisms of metastatic progression by YB-1. Cell Cycle 8, 2901-2906. doi: $10.4161 /$ cc.8.18.9537

Ewert, L., Fischer, A., Brandt, S., Scurt, F. G., Philipsen, L., Müller, A. J., et al. (2018). Cold shock Y-box binding protein1 acetylation status in monocytes is associated with systemic inflammation and vascular damage. Atherosclerosis 278, 156-165. doi: 10.1016/j.atherosclerosis.2018.09.020

Ferreira, A., Bettencourt, M., Alho, I., Costa, A., Sousa, A., Mansinho, A., et al. (2017). Serum YB-1 (Y-box binding protein 1) as a biomarker of bone disease progression in patients with breast cancer and bone metastases. J. Bone Oncol. 6, 16-21. doi: 10.1016/j.jbo.2017.01.002

Fomina, E., Pestryakov, P., Maltseva, E., Petruseva, I., Kretov, D., Ovchinnikov, L., et al. (2015). Y-box binding protein 1 (YB-1) promotes detection of DNA bulky lesions by XPC-HR23B factor. Biochemistry 80, 219-227. doi: 10.1134/ S000629791502008X

Forde, P. M., Scherpereel, A., and Tsao, A. S. (2019). Use of immune checkpoint inhibitors in mesothelioma. Curr. Treat. Options Oncol. 20:18. doi: 10.1007/ s11864-019-0613-x

Friedlaender, A., Banna, G., Malapelle, U., Pisapia, P., and Addeo, A. (2019). Next generation sequencing and genetic alterations in squamous cell lung carcinoma: where are we today? Front. Oncol. 9:166. doi: 10.3389/fonc.2019.00166

Frye, B. C., Halfter, S., Djudjaj, S., Muehlenberg, P., Weber, S., Raffetseder, U., et al. (2009). Y-box protein-1 is actively secreted through a non-classical pathway and acts as an extracellular mitogen. EMBO Rep. 10, 783-789. doi: 10.1038/embor. 2009.81

Gao, J., Aksoy, B. A., Dogrusoz, U., Dresdner, G., Gross, B., Sumer, S. O., et al. (2013). Integrative analysis of complex cancer genomics and clinical profiles using the cBioPortal. Sci. Signal. 6:11. doi: 10.1126/scisignal.2004088

Gaudreault, I., Guay, D., and Lebel, M. (2004). YB-1 promotes strand separation in vitro of duplex DNA containing either mispaired bases or cisplatin modifications, exhibits endonucleolytic activities and binds several DNA repair proteins. Nucleic Acids Res. 32, 316-327. doi: 10.1093/nar/gkh170
Gera, S., and Dighe, R. R. (2018). The soluble ligand Ybox-1 activates Notch3 receptor by binding to epidermal growth factor like repeats 20-23. Arch. Biochem. Biophys. 660, 129-136. doi: 10.1016/j.abb.2018.10.009

Gessner, C., Woischwill, C., Schumacher, A., Liebers, U., Kuhn, H., Stiehl, P., et al. (2004). Nuclear YB-1 expression as a negative prognostic marker in nonsmall cell lung cancer. Eur. Respir. J. 23, 14-19. doi: 10.1183/09031936.03.00033203

Gopal, S. K., Greening, D. W., Mathias, R. A., Ji, H., Rai, A., Chen, M., et al. (2015). YBX1/YB-1 induces partial EMT and tumourigenicity through secretion of angiogenic factors into the extracellular microenvironment. Oncotarget 6:13718.

Goswami, C. P., and Nakshatri, H. (2014). PROGgeneV2: enhancements on the existing database. BMC Cancer 14:970. doi: 10.1186/1471-2407-14-970

Greening, D. W., Ji, H., Chen, M., Robinson, B. W., Dick, I. M., Creaney, J., et al. (2016). Secreted primary human malignant mesothelioma exosome signature reflects oncogenic cargo. Sci. Rep. 6:32643. doi: 10.1038/srep 32643

Guarino, A., Troiano, A., Pizzo, E., Bosso, A., Vivo, M., Pinto, G., et al. (2018). Oxidative stress causes enhanced secretion of YB-1 Protein that restrains proliferation of receiving cells. Genes. 9:E513. doi: 10.3390/genes9100513

Gujral, T. S., Chan, M., Peshkin, L., Sorger, P. K., Kirschner, M. W., and MacBeath, G. (2014). A noncanonical Frizzled2 pathway regulates epithelial-mesenchymal transition and metastasis. Cell 159, 844-856. doi: 10.1016/j.cell.2014. 10.032

Gunasekaran, V. P., Nishi, K., Sivakumar, D., Sivaraman, T., and Mathan, G. (2018). Identification of 2, 4-dihydroxy-5-pyrimidinyl imidothiocarbomate as a novel inhibitor to $\mathrm{Y}$ box binding protein-1 (YB-1) and its therapeutic actions against breast cancer. Eur. J. Pharm. Sci. 116, 2-14. doi: 10.1016/j.ejps.2017. 09.019

Guo, T., Kong, J., Liu, Y., Li, Z., Xia, J., Zhang, Y., et al. (2017). Transcriptional activation of NANOG by YBX1 promotes lung cancer stem-like properties and metastasis. Biochem. Biophys. Res. Commun. 487, 153-159. doi: 10.1016/j.bbrc. 2017.04.033

Gutschner, T., Richtig, G., Haemmerle, M., and Pichler, M. (2018). From biomarkers to therapeutic targets-the promises and perils of long non-coding RNAs in cancer. Cancer Metastasis Rev. 37, 83-105. doi: 10.1007/s10555-0179718-5

Győrffy, B., Surowiak, P., Budczies, J., and Lánczky, A. (2013). Online survival analysis software to assess the prognostic value of biomarkers using transcriptomic data in non-small-cell lung cancer. PLoS One 8:e82241. doi: 10.1371/journal.pone.0082241

Ha, B., Lee, E. B., Cui, J., Kim, Y., and Jang, H. H. (2015). YB-1 overexpression promotes a TGF- $\beta 1$-induced epithelial-mesenchymal transition via Akt activation. Biochem. Biophys. Res. Commun. 458, 347-351. doi: 10.1016/j.bbrc. 2015.01.114

Hansen, J. (2017). Night shift work and risk of breast cancer. Curr. Environ. Health Rep. 4, 325-339. doi: 10.1007/s40572-017-0155-y

Harada, M., Kotake, Y., Ohhata, T., Kitagawa, K., Niida, H., Matsuura, S., et al. (2014). YB-1 promotes transcription of cyclin D1 in human non-small-cell lung cancers. Genes Cells 19, 504-516. doi: 10.1111/gtc.12150

He, L., Che, M., Hu, J., Li, S., Jia, Z., Lou, W., et al. (2015). Twist contributes to proliferation and epithelial-to-mesenchymal transition-induced fibrosis by regulating YB-1 in human peritoneal mesothelial cells. Am. J. Pathol. 185, 2181-2193. doi: 10.1016/j.ajpath.2015.04.008

Hermann, P. C., Huber, S. L., Herrler, T., Aicher, A., Ellwart, J. W., Guba, M., et al. (2007). Distinct populations of cancer stem cells determine tumor growth and metastatic activity in human pancreatic cancer. Cell Stem Cell 1, 313-323. doi: 10.1016/j.stem.2007.06.002

Hirsch, F. R., Scagliotti, G. V., Mulshine, J. L., Kwon, R., Curran , W. J. Jr., Wu, Y.-L., et al. (2017). Lung cancer: current therapies and new targeted treatments. Lancet 389, 299-311. doi: 10.1016/s0140-6736(16)30958-8

Hoda, M. A., Mohamed, A., Ghanim, B., Filipits, M., Hegedus, B., Tamura, M., et al. (2011). Temsirolimus inhibits malignant pleural mesothelioma growth in vitro and in vivo: synergism with chemotherapy. J. Thorac. Oncol. 6, 852-863. doi: 10.1097/JTO.0b013e31820e1a25

Hyogotani, A., Ito, K.-I., Yoshida, K., Izumi, H., Kohno, K., and Amano, J. (2012). Association of nuclear YB-1 localization with lung resistance-related protein and epidermal growth factor receptor expression in lung cancer. Clin. Lung Cancer 13, 375-384. doi: 10.1016/j.cllc.2011.11.006 
Ise, T., Nagatani, G., Imamura, T., Kato, K., Takano, H., Nomoto, M., et al. (1999). Transcription factor Y-box binding protein 1 binds preferentially to cisplatinmodified DNA and interacts with proliferating cell nuclear antigen. Cancer Res. 59, 342-346.

Islami, F., Torre, L. A., and Jemal, A. (2015). Global trends of lung cancer mortality and smoking prevalence. Transl. Lung Cancer Res. 4, 327-338. doi: 10.3978/j. issn.2218-6751.2015.08.04

Iwanami, T., Uramoto, H., Nakagawa, M., Shimokawa, H., Yamada, S., Kohno, K., et al. (2014). Clinical significance of epithelial-mesenchymal transitionassociated markers in malignant pleural mesothelioma. Oncology 86, 109-116. doi: 10.1159/000356874

Jamal-Hanjani, M., Wilson, G. A., McGranahan, N., Birkbak, N. J., Watkins, T. B., Veeriah, S., et al. (2017). Tracking the evolution of non-small-cell lung cancer. N. Engl. J. Med. 376, 2109-2121.

Janku, F., Yap, T. A., and Meric-Bernstam, F. (2018). Targeting the PI3K pathway in cancer: are we making headway? Nat. Rev. Clin. Oncol. 15, 273-291. doi: 10.1038/nrclinonc.2018.28

Jia, J., Zheng, Y., Wang, W., Shao, Y., Li, Z., Wang, Q., et al. (2017). Antimicrobial peptide LL-37 promotes YB-1 expression, and the viability, migration and invasion of malignant melanoma cells. Mol. Med. Rep. 15, 240-248. doi: 10. 3892/mmr.2016.5978

Jiang, L., Yuan, G.-L., Liang, Q.-L., Zhang, H.-J., Huang, J., Cheng, S.-A., et al. (2017). Positive expression of Y-box binding protein 1 and prognosis in nonsmall cell lung cancer: a meta-analysis. Oncotarget 8:55613. doi: 10.18632/ oncotarget.14732

Jiang, W., Kahn, S. M., Tomita, N., Zhang, Y.-J., Lu, S.-H., and Weinstein, I. B. (1992). Amplification and expression of the human cyclin D gene in esophageal cancer. Cancer Res. 52, 2980-2983.

Jin, B., Dong, Y., Zhang, X., Wang, H., and Han, B. (2014). Association of XPC polymorphisms and lung cancer risk: a meta-analysis. PLoS One 9:e93937. doi: 10.1371/journal.pone.0093937

Johnson, T. G., Schelch, K., Cheng, Y. Y., Williams, M., Sarun, K. H., Kirschner, M. B., et al. (2018). Dysregulated expression of the MicroRNA miR-137 and its target YBX1 contribute to the invasive characteristics of malignant pleural mesothelioma. J. Thorac. Oncol. 13, 258-272. doi: 10.1016/j.jtho.2017.10.016

Jonas, S., and Izaurralde, E. (2015). Towards a molecular understanding of microRNA-mediated gene silencing. Nat. Rev. Genet. 16, 421-433. doi: 10.1038/ $\operatorname{nrg} 3965$

Jung, K., Wu, F., Wang, P., Ye, X., Abdulkarim, B. S., and Lai, R. (2014). YB1 regulates Sox 2 to coordinately sustain stemness and tumorigenic properties in a phenotypically distinct subset of breast cancer cells. BMC Cancer 14:328. doi: 10.1186/1471-2407-14-328

Kang, Y., Hu, W., Ivan, C., Dalton, H. J., Miyake, T., Pecot, C. V., et al. (2013). Role of focal adhesion kinase in regulating YB-1-mediated paclitaxel resistance in ovarian cancer. J. Natl. Cancer Inst. 105, 1485-1495. doi: 10.1093/jnci/djt210

Karachaliou, N., Rosell, R., and Viteri, S. (2013). The role of SOX2 in small cell lung cancer, lung adenocarcinoma and squamous cell carcinoma of the lung. Transl. Lung Cancer Res. 2, 172-179. doi: 10.3978/j.issn.2218-6751.2013.01.01

Kasyapa, C., Gu, T. L., Natarajan, L., Polakiewicz, R., and Cowell, J. K. (2009). Phosphorylation of the SSBP2 and ABL proteins by the ZNF198-FGFR1 fusion kinase seen in atypical myeloproliferative disorders as revealed by phosphopeptide-specific MS. Proteomics 9, 3979-3988. doi: 10.1002/pmic. 200800852

Khan, M. I., Adhami, V. M., Lall, R. K., Sechi, M., Joshi, D. C., Haidar, O. M., et al. (2014). YB-1 expression promotes epithelial-to-mesenchymal transition in prostate cancer that is inhibited by a small molecule fisetin. Oncotarget 5 , 2462-2474.

Khan, N., Afaq, F., Khusro, F. H., Adhami, V. M., Suh, Y., and Mukhtar, H. (2012). Dual inhibition of phosphatidylinositol 3-kinase/Akt and mammalian target of rapamycin signaling in human nonsmall cell lung cancer cells by a dietary flavonoid fisetin. Int. J. Cancer 130, 1695-1705. doi: 10.1002/ijc.26178

Khuder, S. A. (2001). Effect of cigarette smoking on major histological types of lung cancer: a meta-analysis. Lung Cancer 31, 139-148. doi: 10.1016/s0169-5002(00) 00181- 1

Kim, E. R., Selyutina, A. A., Buldakov, I. A., Evdokimova, V., Ovchinnikov, L. P., and Sorokin, A. V. (2013). The proteolytic YB-1 fragment interacts with DNA repair machinery and enhances survival during DNA damaging stress. Cell Cycle 12, 3791-3803. doi: 10.4161/cc.26670
Kim, M.-C., Hwang, S.-H., Kim, N.-Y., Lee, H.-S., Ji, S., Yang, Y., et al. (2018). Hypoxia promotes acquisition of aggressive phenotypes in human malignant mesothelioma. BMC Cancer 18:819. doi: 10.1186/s12885-018-4720-z

Kobayashi, I., Takahashi, F., Nurwidya, F., Nara, T., Hashimoto, M., Murakami, A., et al. (2016). Oct4 plays a crucial role in the maintenance of gefitinibresistant lung cancer stem cells. Biochem. Biophys. Res. Commun. 473, 125-132. doi: 10.1016/j.bbrc.2016.03.064

Koike, K., Uchiumi, T., Ohga, T., Toh, S., Wada, M., Kohno, K., et al. (1997). Nuclear translocation of the Y-box binding protein by ultraviolet irradiation. FEBS Lett. 417, 390-394. doi: 10.1016/s0014-5793(97)01296-9

Kosnopfel, C., Sinnberg, T., and Schittek, B. (2014). Y-box binding protein 1-a prognostic marker and target in tumour therapy. Eur. J. Cell Biol. 93, 61-70. doi: 10.1016/j.ejcb.2013.11.007

Kris, M. G., Gaspar, L. E., Chaft, J. E., Kennedy, E. B., Azzoli, C. G., Ellis, P. M., et al. (2017). Adjuvant systemic therapy and adjuvant radiation therapy for stage I to IIIA completely resected non-small-cell lung cancers: American Society of Clinical Oncology/Cancer Care Ontario clinical practice guideline update. J. Clin. Oncol. 35, 2960-2974. doi: 10.1200/JCO.2017.72.4401

Kröger, C., Afeyan, A., Mraz, J., Eaton, E. N., Reinhardt, F., Khodor, Y. L., et al. (2019). Acquisition of a hybrid E/M state is essential for tumorigenicity of basal breast cancer cells. Proc. Natl. Acad. Sci. 116, 7353-7362. doi: 10.1073/pnas. 1812876116

Kwon, P., Lundin, J., Li, W., Ray, R., Littell, C., Gao, D., et al. (2015). Night shift work and lung cancer risk among female textile workers in shanghai, china. J. Occup. Environ. Hyg. 12, 334-341. doi: 10.1080/15459624.2014.993472

Ladanyi, M. (2005). Implications of P16/CDKN2A deletion in pleural mesotheliomas. Lung Cancer 49, S95-S98.

Lara, P. C., Pruschy, M., Zimmermann, M., and Henríquez-Hernández, L. A. (2011). MVP and vaults: a role in the radiation response. Radiat. Oncol. 6:148. doi: 10.1186/1748-717X-6-148

Lasham, A., Samuel, W., Cao, H., Patel, R., Mehta, R., Stern, J. L., et al. (2011). YB1 , the E2F pathway, and regulation of tumor cell growth. J. Natl. Cancer Inst. 104, 133-146. doi: 10.1093/jnci/djr512

Lasham, A., Woolley, A. G., Dunn, S. E., and Braithwaite, A. W. (2013). YB-1: oncoprotein, prognostic marker and therapeutic target? Biochem. J. 449, 11-23. doi: $10.1042 /$ bj20121323

Law, J. H., Li, Y., To, K., Wang, M., Astanehe, A., Lambie, K., et al. (2010). Molecular decoy to the Y-box binding protein-1 suppresses the growth of breast and prostate cancer cells whilst sparing normal cell viability. PLoS One 5:e12661. doi: 10.1371/journal.pone.0012661

Lee, H.-Y., Mohammed, K. A., and Nasreen, N. (2016). Nanoparticle-based targeted gene therapy for lung cancer. Am. J. Cancer Res. 6, 1118-1134.

Leon, G., MacDonagh, L., Finn, S. P., Cuffe, S., and Barr, M. P. (2016). Cancer stem cells in drug resistant lung cancer: targeting cell surface markers and signaling pathways. Pharmacol. Ther. 158, 71-90. doi: 10.1016/j.pharmthera.2015.12.001

Li, D., Liu, X., Zhou, J., Hu, J., Zhang, D., Liu, J., et al. (2017). Long noncoding RNA HULC modulates the phosphorylation of YB-1 through serving as a scaffold of extracellular signal-regulated kinase and YB-1 to enhance hepatocarcinogenesis. Hepatology 65, 1612-1627. doi: 10.1002/hep.29010

Li, J., Li, Z.-N., Du, Y.-J., Li, X.-Q., Bao, Q.-L., and Chen, P. (2009). Expression of MRP1, BCRP, LRP, and ERCC1 in advanced non-small-cell lung cancer: correlation with response to chemotherapy and survival. Clin. Lung Cancer 10, 414-421. doi: 10.3816/CLC.2009.n.078

Li, M., Zhang, X., Xu, X., Wu, J., Hu, K., Guo, X., et al. (2018). Clinicopathological and prognostic significance of Twist overexpression in NSCLC. Oncotarget 9 , 14642-14651. doi: 10.18632/oncotarget.24489

Li, X.-Q., Li, J., Shi, S.-B., Chen, P., Yu, L.-C., and Bao, Q.-L. (2009). Expression of MRP1, BCRP, LRP and ERCC1 as prognostic factors in non-small cell lung cancer patients receiving postoperative cisplatin-based chemotherapy. Int. J. Biol. Mark. 24, 230-237. doi: 10.5301/jbm.2009. 5437

Li, Z., and Rich, J. N. (2010). Hypoxia and hypoxia inducible factors in cancer stem cell maintenance. Curr. Top. Microbiol. Immunol. 345, 21-30. doi: 10.1007/82_ 2010_75

Liang, C., Ma, Y., Yong, L., Yang, C., Wang, P., Liu, X., et al. (2019). Y-box binding protein-1 promotes tumorigenesis and progression via the epidermal growth factor receptor/AKT pathway in spinal chordoma. Cancer Sci. 110:166. doi: $10.1111 /$ cas. 13875 
Lichtenegger, E., Koll, F., Haas, H., Mantwill, K., Janssen, K.-P., Laschinger, M., et al. (2018). The oncolytic adenovirus XVir-N-31 as a novel therapy in muscle-invasive bladder cancer. Hum. Gene Ther. 30, 44-56. doi: 10.1089/hum. 2018.026

Lim, J. P., Shyamasundar, S., Gunaratne, J., Scully, O. J., Matsumoto, K., and Bay, B. H. (2017). YBX1 gene silencing inhibits migratory and invasive potential via CORO1C in breast cancer in vitro. BMC Cancer 17:201. doi: 10.1186/s12885017-3187-7

Lindquist, K. E., Karlsson, A., Levéen, P., Brunnström, H., Reuterswärd, C. Holm, K., et al. (2017). Clinical framework for next generation sequencing based analysis of treatment predictive mutations and multiplexed gene fusion detection in non-small cell lung cancer. Oncotarget 8, 34796-34810. doi: 10. 18632/oncotarget.16276

Liu, L., Zhou, X., Zhang, J., Wang, G., He, J., Chen, Y., et al. (2018). LncRNA HULC promotes non-small cell lung cancer cell proliferation and inhibits the apoptosis by up-regulating sphingosine kinase 1 (SPHK1) and its downstream PI3K/Akt pathway. Eur. Rev. Med. Pharmacol. Sci. 22, 8722-8730. doi: 10.26355/eurrev_ 201812_16637

Liu, Q., Tao, T., Liu, F., Ni, R., Lu, C., and Shen, A. (2016). Hyper-O-GlcNAcylation of YB-1 affects Ser102 phosphorylation and promotes cell proliferation in hepatocellular carcinoma. Exp. Cell Res. 349, 230-238. doi: 10.1016/j.yexcr. 2016.10.011

Liu, W., Zhou, Z., Dong, D., Sun, L., and Zhang, G. (2018). Sex differences in the association between night shift work and the risk of cancers: a meta-analysis of 57 articles. Dis. Mark. 2018:7925219. doi: 10.1155/2018/7925219

Liu, Y., Zhao, J., Zhang, W., Gan, J., Hu, C., Huang, G., et al. (2015). IncRNA GAS5 enhances $\mathrm{G} 1$ cell cycle arrest via binding to $\mathrm{YBX} 1$ to regulate $\mathrm{p} 21$ expression in stomach cancer. Sci. Rep. 5:10159. doi: 10.1038/srep10159

Lu, J., Li, X., Wang, F., Guo, Y., Huang, Y., Zhu, H., et al. (2017). YB-1 expression promotes pancreatic cancer metastasis that is inhibited by microRNA-216a Exp. Cell Res. 359, 319-326. doi: 10.1016/j.yexcr.2017.07.039

Lyabin, D. N., Eliseeva, I. A., and Ovchinnikov, L. P. (2012). YB-1 synthesis is regulated by mTOR signaling pathway. PLoS One 7:e52527. doi: 10.1371/ journal.pone.0052527

Lyabin, D. N., Eliseeva, I. A., and Ovchinnikov, L. P. (2014). YB-1 protein: functions and regulation. Wiley Interdiscipl. Rev. RNA 5, 95-110. doi: 10.1002/wrna.1200

Ma, S., Musa, T., and Bag, J. (2006). Reduced stability of mitogen-activated protein kinase kinase-2 mRNA and phosphorylation of poly (A)-binding protein (PABP) in cells overexpressing PABP. J. Biol. Chem. 281, 3145-3156. doi: 10.1074/jbc.m508937200

MacDonagh, L., Gray, S. G., Breen, E., Cuffe, S., Finn, S. P., O’Byrne, K. J., et al. (2016). Lung cancer stem cells: the root of resistance. Cancer Lett. 372, 147-156. doi: 10.1016/j.canlet.2016.01.012

Makena, M. R., Ranjan, A., Thirumala, V., and Reddy, A. (2018). Cancer stem cells: road to therapeutic resistance and strategies to overcome resistance. Biochim. Biophys. Acta Mol. Basis Dis. doi: 10.1016/j.bbadis.2018.11.015 [Epub ahead of print].

Makino, Y., Ohga, T., Toh, S., Koike, K., Okumura, K., Wada, M., et al. (1996). Structural and functional analysis of the human Y-box binding protein (YB-1) gene promoter. Nucleic Acids Res. 24, 1873-1878. doi: 10.1093/nar/24.10.1873

Mantwill, K., Köhler-Vargas, N., Bernshausen, A., Bieler, A., Lage, H., Kaszubiak, A., et al. (2006). Inhibition of the multidrug-resistant phenotype by targeting YB-1 with a conditionally oncolytic adenovirus: implications for combinatorial treatment regimen with chemotherapeutic agents. Cancer Res. 66, 7195-7202. doi: 10.1158/0008-5472.can-05-2339

Mantwill, K., Naumann, U., Seznec, J., Girbinger, V., Lage, H., Surowiak, P., et al. (2013). YB-1 dependent oncolytic adenovirus efficiently inhibits tumor growth of glioma cancer stem like cells. J. Transl. Med. 11:216. doi: 10.1186/1479-587611-216

Marshall, A., Bayes, H., Bardgett, J., Wedderburn, S., Kerr, K., and Currie, G. (2015). Survival from malignant mesothelioma: where are we now? J. R. Coll. Phys. Edinburgh 45, 123-126. doi: 10.4997/JRCPE.2015.207

Martin, M., Hua, L., Wang, B., Wei, H., Prabhu, L., Hartley, A.-V., et al. (2017). Novel Serine 176 phosphorylation of YBX1 activates NF- $\mathrm{B}$ in colon cancer. J. Biol. Chem. 292, 3433-3444. doi: 10.1074/jbc.M116.740258

Mashouri, L., Yousefi, H., Aref, A. R., Mohammad Ahadi, A., Molaei, F., and Alahari, S. K. (2019). Exosomes: composition, biogenesis, and mechanisms in cancer metastasis and drug resistance. Mol. Cancer 18:75.
Matsumoto, K., Kose, S., Kuwahara, I., Yoshimura, M., Imamoto, N., and Yoshida, M. (2018). Y-box protein-associated acidic protein (YBAP1/C1QBP) affects the localization and cytoplasmic functions of YB-1. Sci. Rep. 8:6198. doi: 10.1038/ s41598-018-24401-3

Mendoza, M. C., Er, E. E., and Blenis, J. (2011). The Ras-ERK and PI3K-mTOR pathways: cross-talk and compensation. Trends Biochem. Sci. 36, 320-328. doi: 10.1016/j.tibs.2011.03.006

Mordovkina, D. A., Kim, E. R., Buldakov, I. A., Sorokin, A. V., Eliseeva, I. A., Lyabin, D. N., et al. (2016). Transportin-1-dependent YB-1 nuclear import. Biochem. Biophys. Res. Commun. 480, 629-634. doi: 10.1016/j.bbrc.2016. 10.107

Munson, P., Lam, Y.-W., Dragon, J., MacPherson, M., and Shukla, A. (2018). Exosomes from asbestos-exposed cells modulate gene expression in mesothelial cells. FASEB J. 32, 4328-4342. doi: 10.1096/fj.201701291RR

Murugesan, S. N., Yadav, B. S., Maurya, P. K., Chaudhary, A., Singh, S., and Mani, A. (2018). Expression and network analysis of YBX1 interactors for identification of new drug targets in lung adenocarcinoma. J. Genomics 6, 103-112. doi: 10.7150/jgen.20581

Mutti, L., Peikert, T., Robinson, B. W., Scherpereel, A., Tsao, A. S., de Perrot, M., et al. (2018). Scientific advances and new frontiers in mesothelioma therapeutics. J. Thorac. Oncol. 13, 1269-1283. doi: 10.1016/j.jtho.2018.06.011

Muz, B., de la Puente, P., Azab, F., and Azab, A. K. (2015). The role of hypoxia in cancer progression, angiogenesis, metastasis, and resistance to therapy. Hypoxia 3, 83-92.

Nagasaka, M., and Gadgeel, S. M. (2018). Role of chemotherapy and targeted therapy in early-stage non-small cell lung cancer. Expert Rev. Anticancer Ther. 18, 63-70. doi: 10.1080/14737140.2018.1409624

Nishikawa, S., Tanaka, A., Matsuda, A., Oida, K., Jang, H., Jung, K., et al. (2014). A molecular targeting against nuclear factor- $\mathrm{\kappa}$, as a chemotherapeutic approach for human malignant mesothelioma. Cancer Med. 3, 416-425. doi: 10.1002/ cam 4.202

Ohga, T., Uchiumi, T., Makino, Y., Koike, K., Wada, M., Kuwano, M., et al. (1998). Direct involvement of the Y-box binding protein YB-1 in genotoxic stressinduced activation of the human multidrug resistance 1 gene. J. Biol. Chem. 273, 5997-6000. doi: 10.1074/jbc.273.11.5997

Oronsky, B., Reid, T. R., Oronsky, A., and Carter, C. A. (2017). What's new in SCLC? a review. Neoplasia 19, 842-847. doi: 10.1016/j.neo.2017.07.007

Ott, P. A., Fernandez, M. E. E., Hiret, S., Kim, D.-W., Moss, R. A., Winser, T., et al. (2015). Pembrolizumab (MK-3475) in patients (pts) with extensive-stage small cell lung cancer (SCLC): preliminary safety and efficacy results from KEYNOTE-028. J. Clin. Oncol. 33(Suppl. 15), 7502-7502. doi: 10.1200/jco. 2015.33.15_suppl.7502

Pagano, C., di Martino, O., Ruggiero, G., Guarino, A. M., Mueller, N., Siauciunaite, R., et al. (2017). The tumor-associated YB-1 protein: new player in the circadian control of cell proliferation. Oncotarget 8, 6193-6205. doi: 10.18632/oncotarget. 14051

Palicharla, V. R., and Maddika, S. (2015). HACE1 mediated K27 ubiquitin linkage leads to YB-1 protein secretion. Cell Signal. 27, 2355-2362. doi: 10.1016/j.cellsig. 2015.09.001

Papagiannakopoulos, T., Bauer, M. R., Davidson, S. M., Heimann, M., Subbaraj, L., Bhutkar, A., et al. (2016). Circadian rhythm disruption promotes lung tumorigenesis. Cell Metab. 24, 324-331. doi: 10.1016/j.cmet.2016.07.001

Park, H. S., Kim, S. R., and Lee, Y. C. (2009). Impact of oxidative stress on lung diseases. Respirology 14, 27-38. doi: 10.1111/j.1440-1843.2008.01447.x

Pastushenko, I., Brisebarre, A., Sifrim, A., Fioramonti, M., Revenco, T., Boumahdi, S., et al. (2018). Identification of the tumour transition states occurring during EMT. Nature 556, 463-468. doi: 10.1038/s41586-018-0040-3

Peng, Z., Wang, J., Shan, B., Li, B., Peng, W., Dong, Y., et al. (2018). The long noncoding RNA LINC00312 induces lung adenocarcinoma migration and vasculogenic mimicry through directly binding YBX1. Mol. Cancer 17:167. doi: 10.1186/s12943-018-0920-z

Poomakkoth, N., Issa, A., Abdulrahman, N., Abdelaziz, S. G., and Mraiche, F. (2016). p90 ribosomal S6 kinase: a potential therapeutic target in lung cancer. J. Transl. Med. 14:14. doi: 10.1186/s12967-016-0768-1

Prabhu, L., Mundade, R., Wang, B., Wei, H., Hartley, A.-V., Martin, M., et al. (2015). Critical role of phosphorylation of serine 165 of YBX1 on the activation of NF-кB in colon cancer. Oncotarget 6, 29396-29412. doi: 10.18632/oncotarget. 5120 
Quispel-Janssen, J. M., Badhai, J., Schunselaar, L., Price, S., Brammeld, J., Iorio, F., et al. (2018). Comprehensive pharmacogenomic profiling of malignant pleural mesothelioma identifies a subgroup sensitive to FGFR inhibition. Clin. Cancer Res. 24, 84-94. doi: 10.1158/1078-0432.CCR-17-1172

Raffetseder, U., Rauen, T., Boor, P., Ostendorf, T., Hanssen, L., Floege, J., et al. (2011). Extracellular YB-1 blockade in experimental nephritis upregulates Notch-3 receptor expression and signaling. Nephron Exp. Nephrol. 118, e100e108. doi: 10.1159/000324209

Rauen, T., Frye, B. C., Wang, J., Raffetseder, U., Alidousty, C., En-Nia, A., et al. (2016). Cold shock protein YB-1 is involved in hypoxia-dependent gene transcription. Biochem. Biophys. Res. Commun. 478, 982-987. doi: 10.1016/j. bbrc.2016.08.064

Rauen, T., Raffetseder, U., Frye, B. C., Djudjaj, S., Mühlenberg, P. J., Eitner, F., et al. (2009). YB-1 acts as ligand for Notch-3 receptors and modulates receptor activation. J. Biol. Chem. 284, 26928-26940. doi: 10.1074/jbc.M109.046599

Renganathan, A., Kresoja-Rakic, J., Echeverry, N., Ziltener, G., Vrugt, B., Opitz, I., et al. (2014). GAS5 long non-coding RNA in malignant pleural mesothelioma. Mol. Cancer 13:119. doi: 10.1186/1476-4598-13-119

Reya, T., and Clevers, H. (2005). Wnt signalling in stem cells and cancer. Nature 434, 843-850. doi: 10.1038/nature03319

Riquelme, E., Suraokar, M. B., Rodriguez, J., Mino, B., Lin, H. Y., Rice, D. C., et al. (2014). Frequent coamplification and cooperation between C-MYC and PVT1 oncogenes promote malignant pleural mesothelioma. J. Thorac. Oncol. 9, 998-1007. doi: 10.1097/JTO.0000000000000202

Rohwer, N., and Cramer, T. (2011). Hypoxia-mediated drug resistance: novel insights on the functional interaction of HIFs and cell death pathways. Drug Resist. Updat. 14, 191-201. doi: 10.1016/j.drup.2011.03.001

Rudin, C. M., Durinck, S., Stawiski, E. W., Poirier, J. T., Modrusan, Z., Shames, D. S., et al. (2012). Comprehensive genomic analysis identifies SOX2 as a frequently amplified gene in small-cell lung cancer. Nat. Genet. 44, 1111-1116. doi: $10.1038 / \mathrm{ng} .2405$

Rudin, C. M., Giaccone, G., and Ismaila, N. (2016). Treatment of small-cell lung cancer: American Society of Clinical Oncology endorsement of the American College of Chest Physicians guideline. J. Oncol. Pract. 12, 83-86. doi: 10.1200/ jop.2015.008201

Ryu, A., Kim, D. H., Kim, E., and Lee, M. Y. (2018). The potential roles of extracellular vesicles in cigarette smoke-associated diseases. Oxidat. Med. Cell. Longev. 2018:4692081. doi: 10.1155/2018/4692081

Schelch, K., Hoda, M. A., Klikovits, T., Münzker, J., Ghanim, B., Wagner, C., et al. (2014). Fibroblast growth factor receptor inhibition is active against mesothelioma and synergizes with radio-and chemotherapy. Am. J. Respir. Crit. Care Med. 190, 763-772. doi: 10.1164/rccm.201404-0658OC

Schittek, B., Psenner, K., Sauer, B., Meier, F., Iftner, T., and Garbe, C. (2007). The increased expression of $\mathrm{Y}$ box-binding protein 1 in melanoma stimulates proliferation and tumor invasion, antagonizes apoptosis and enhances chemoresistance. Int. J. Cancer 120, 2110-2118. doi: 10.1002/ijc.22512

Sears, C. R. (2019). DNA repair as an emerging target for COPD-lung cancer overlap. Respir. Investig. 57, 111-121. doi: 10.1016/j.resinv.2018.11.005

Sechi, M., Lall, R. K., Afolabi, S. O., Singh, A., Joshi, D. C., Chiu, S.-Y., et al. (2018). Fisetin targets YB-1/RSK axis independent of its effect on ERK signaling: insights from in vitro and in vivo melanoma models. Sci. Rep. 8:15726. doi: 10.1038/s41598-018-33879-w

Sementino, E., Menges, C. W., Kadariya, Y., Peri, S., Xu, J., Liu, Z., et al. (2018). Inactivation of Tp53 and Pten drives rapid development of pleural and peritoneal malignant mesotheliomas. J. Cell. Physiol. 233, 8952-8961. doi: $10.1002 /$ jcp. 26830

Semenza, G. L. (2014). Oxygen sensing, hypoxia-inducible factors, and disease pathophysiology. Annu. Rev. Pathol. Mech. Dis. 9, 47-71. doi: 10.1146/annurev-pathol-012513-104720

Seton-Rogers, S. (2012). Therapeutics: siRNAs jump the hurdle. Nat. Rev. Cancer 12, 376-377. doi: 10.1038/nrc3281

Shi, J. H., Cui, N. P., Wang, S., Zhao, M. Z., Wang, B., Wang, Y. N., et al. (2016). Overexpression of YB 1 C-terminal domain inhibits proliferation, angiogenesis and tumorigenicity in a SK-BR-3 breast cancer xenograft mouse model. FEBS Open Bio. 6, 33-42. doi: 10.1002/2211-5463.12004

Shi, X., Sun, M., Liu, H., Yao, Y., Kong, R., Chen, F., et al. (2015). A critical role for the long non-coding RNA GAS5 in proliferation and apoptosis in non-small-cell lung cancer. Mol. Carcinog. 54, E1-E12. doi: 10.1002/mc.22120
Shibahara, K., Sugio, K., Osaki, T., Uchiumi, T., Maehara, Y., Kohno, K., et al. (2001). Nuclear expression of the Y-box binding protein, YB-1, as a novel marker of disease progression in non-small cell lung cancer. Clin. Cancer Res. 7, 3151-3155.

Shiota, M., Itsumi, M., Yokomizo, A., Takeuchi, A., Imada, K., Kashiwagi, E., et al. (2014). Targeting ribosomal S6 kinases/Y-box binding protein-1 signaling improves cellular sensitivity to taxane in prostate cancer. Prostate 74, 829-838. doi: 10.1002/pros.22799

Shiota, M., Izumi, H., Onitsuka, T., Miyamoto, N., Kashiwagi, E., Kidani, A., et al. (2008). Twist promotes tumor cell growth through YB-1 expression. Cancer Res. 68, 98-105. doi: 10.1158/0008-5472.CAN-07-2981

Shiota, M., Yokomizo, A., Itsumi, M., Uchiumi, T., Tada, Y., Song, Y., et al. (2011). Twistl and Y-box-binding protein-1 promote malignant potential in bladder cancer cells. BJU Int. 108, E142-E149. doi: 10.1111/j.1464-410X.2010.09810.x

Shiota, M., Yokomizo, A., Tada, Y., Uchiumi, T., Inokuchi, J., Tatsugami, K., et al. (2010). P300/CBP-associated factor regulates Y-box binding protein1 expression and promotes cancer cell growth, cancer invasion and drug resistance. Cancer Sci. 101, 1797-1806. doi: 10.1111/j.1349-7006.2010.01598.x

Shu, Y., Pi, F., Sharma, A., Rajabi, M., Haque, F., Shu, D., et al. (2014). Stable RNA nanoparticles as potential new generation drugs for cancer therapy. Adv. Drug Deliv. Rev. 66, 74-89. doi: 10.1016/j.addr.2013.11.006

Shurtleff, M. J., Yao, J., Qin, Y., Nottingham, R. M., Temoche-Diaz, M. M., Schekman, R., et al. (2017). Broad role for YBX1 in defining the small noncoding RNA composition of exosomes. Proc. Natl. Acad. Sci. U.S.A. 114, E8987-E8995. doi: 10.1073/pnas.1712108114

Singh, A., Bhattacharyya, N., Srivastava, A., Pruett, N., Ripley, R. T., Schrump, D. S., et al. (2019). microRNA-215-5p treatment suppresses mesothelioma progression via the MDM2-p53 signaling axis. Mol. Ther. 27, 1665-1680. doi: 10.1016/j.ymthe.2019.05.020

Singhal, S., Wiewrodt, R., Malden, L. D., Amin, K. M., Matzie, K., Friedberg, J., et al. (2003). Gene expression profiling of malignant mesothelioma. Clin. Cancer Res. 9, 3080-3097.

Skabkina, O. V., Lyabin, D. N., Skabkin, M. A., and Ovchinnikov, L. P. (2005). YB-1 autoregulates translation of its own mRNA at or prior to the step of $40 \mathrm{~S}$ ribosomal subunit joining. Mol. Cell. Biol. 25, 3317-3323. doi: 10.1128/mcb.25. 8.3317-3323.2005

Skabkina, O. V., Skabkin, M. A., Popova, N. V., Lyabin, D. N., Penalva, L. O., and Ovchinnikov, L. P. (2003). Poly (A)-binding protein positively affects YB-1 mRNA translation through specific interaction with YB-1 mRNA. J. Biol. Chem. 278, 18191-18198. doi: 10.1074/jbc.m209073200

Soini, Y., Järvinen, K., Kaarteenaho-Wiik, R., and Kinnula, V. (2001). The expression of P-glycoprotein and multidrug resistance proteins 1 and 2 (MRP1 and MRP2) in human malignant mesothelioma. Ann. Oncol. 12, 1239-1245. doi: 10.1023/a:1012292230480

Somasekharan, S. P., El-Naggar, A., Leprivier, G., Cheng, H., Hajee, S., Grunewald, T. G., et al. (2015). YB-1 regulates stress granule formation and tumor progression by translationally activating G3BP1. J. Cell Biol. 208, 913-929. doi: $10.1083 /$ jcb.201411047

Sorokin, A. V., Selyutina, A. A., Skabkin, M. A., Guryanov, S. G., Nazimov, I. V., Richard, C., et al. (2005). Proteasome-mediated cleavage of the Y-box-binding protein 1 is linked to DNA-damage stress response. EMBO J. 24, 3602-3612. doi: 10.1038/sj.emboj.7600830

Stefan, S. M., and Wiese, M. (2019). Small-molecule inhibitors of multidrug resistance-associated protein 1 and related processes: a historic approach and recent advances. Med. Res. Rev. 39, 176-264. doi: 10.1002/med.21510

Stein, U., Bergmann, S., Scheffer, G. L., Scheper, R. J., Royer, H.-D., Schlag, P. M., et al. (2005). YB-1 facilitates basal and 5-fluorouracil-inducible expression of the human major vault protein (MVP) gene. Oncogene 24, 3606-3618. doi: $10.1038 /$ sj.onc. 1208386

Stein, U., Jürchott, K., Walther, W., Bergmann, S., Schlag, P. M., and Royer, H.-D. (2001). Hyperthermia-induced nuclear translocation of transcription factor YB-1 leads to enhanced expression of multidrug resistance-related ABC transporters. J. Biol. Chem. 276, 28562-28569. doi: 10.1074/jbc.m1003 11200

Stratford, A. L., Fry, C. J., Desilets, C., Davies, A. H., Cho, Y. Y., Li, Y., et al. (2008). Y-box binding protein-1 serine 102 is a downstream target of p90 ribosomal S6 kinase in basal-like breast cancer cells. Breast Cancer Res. 10:R99. doi: $10.1186 /$ bcr 2202 
Stratford, A. L., Habibi, G., Astanehe, A., Jiang, H., Hu, K., Park, E., et al. (2007). Epidermal growth factor receptor (EGFR) is transcriptionally induced by the Y-box binding protein-1 (YB-1) and can be inhibited with Iressa in basal-like breast cancer, providing a potential target for therapy. Breast Cancer Res. 9:R61.

Su, W., Feng, S., Chen, X., Yang, X., Mao, R., Guo, C., et al. (2018). Silencing of long non-coding RNA MIR22HG triggers cell survival/death signaling via oncogenes YBX1, MET, and p21 in lung cancer. Cancer Res. 78, 3207-3219. doi: 10.1158/0008-5472.CAN-18-0222

Suresh, P. S., Tsutsumi, R., and Venkatesh, T. (2018). YBX1 at the crossroads of non-coding transcriptome, exosomal, and cytoplasmic granular signaling. Eur. J. Cell Biol. 97, 163-167. doi: 10.1016/j.ejcb.2018.02.003

Sutherland, B. W., Kucab, J., Wu, J., Lee, C., Cheang, M. C., Yorida, E., et al. (2005). Akt phosphorylates the Y-box binding protein 1 at Ser102 located in the cold shock domain and affects the anchorage-independent growth of breast cancer cells. Oncogene 24, 4281-4292. doi: 10.1038/sj.onc.1208590

Szolkowska, M., Blasinska-Przerwa, K., Knetki-Wroblewska, M., Rudzinski, P., and Langfort, R. (2018). Malignant pleural mesothelioma: main topics of American Society of Clinical Oncology clinical practice guidelines for diagnosis and treatment. J. Thorac. Dis. 10(Suppl. 17), S1966-S1970.

Tabata, C., Shibata, E., Tabata, R., Kanemura, S., Mikami, K., Nogi, Y., et al. (2013). Serum HMGB1 as a prognostic marker for malignant pleural mesothelioma. BMC Cancer 13:205. doi: 10.1186/1471-2407-13-205

Tacke, F., Galm, O., Kanig, N., Yagmur, E., Brandt, S., Lindquist, J. A., et al. (2014). High prevalence of Y-box protein-1/p18 fragment in plasma of patients with malignancies of different origin. BMC Cancer 14:33. doi: 10.1186/1471-240714-33

Tagalakis, A. D., Munye, M. M., Ivanova, R., Chen, H., Smith, C. M., Aldossary, A. M., et al. (2018). Effective silencing of ENaC by siRNA delivered with epithelial-targeted nanocomplexes in human cystic fibrosis cells and in mouse lung. Thorax 73, 847-856. doi: 10.1136/thoraxjnl-2017-210670

Takeuchi, A., Shiota, M., Tatsugami, K., Yokomizo, A., Kuroiwa, K., Dejima, T., et al. (2013). YB-1 suppression induces STAT3 proteolysis and sensitizes renal cancer to interferon- $\alpha$. Cancer Immunol. Immunother. 62, 517-527. doi: 10. 1007/s00262-012-1356-8

Tanaka, T., Kasai, M., and Kobayashi, S. (2018). Mechanism responsible for inhibitory effect of indirubin 3'-oxime on anticancer agent-induced YB-1 nuclear translocation in HepG2 human hepatocellular carcinoma cells. Exp. Cell Res. 370, 454-460. doi: 10.1016/j.yexcr.2018.07.009

Tanaka, T., Ohashi, S., and Kobayashi, S. (2016). Four nucleocytoplasmic-shuttling proteins and p53 interact specifically with the YB-NLS and are involved in anticancer reagent-induced nuclear localization of YB-1. Biochem. Biophys. Res. Commun. 478, 1363-1369. doi: 10.1016/j.bbrc.2016.08.129

Tao, Z., Ruan, H., Sun, L., Kuang, D., Song, Y., Wang, Q., et al. (2019). Targeting the YB-1/PD-L1 axis to enhance chemotherapy and antitumor immunity. Cancer Immunol. Res. 7, 1135-1147. doi: 10.1158/2326-6066.CIR-18-0648

Tiwari, A., Rebholz, S., Maier, E., Dehghan Harati, M., Zips, D., Sers, C., et al. (2018). Stress-induced phosphorylation of nuclear YB-1 depends on nuclear trafficking of p90 Ribosomal S6 Kinase. Int. J. Mol. Sci. 19:2441. doi: 10.3390/ ijms 19082441

To, K., Fotovati, A., Reipas, K. M., Law, J. H., Hu, K., Wang, J., et al. (2010). Ybox binding protein-1 induces the expression of CD44 and CD49f leading to enhanced self-renewal, mammosphere growth, and drug resistance. Cancer Res. 70, 2840-2851. doi: 10.1158/0008-5472.can-09-3155

Tossavainen, A. (2004). Global use of asbestos and the incidence of mesothelioma. Int. J. Occup. Environ. Health 10, 22-25. doi: 10.1179/oeh.2004.10.1.22

Uramoto, H., Izumi, H., Ise, T., Tada, M., Uchiumi, T., Kuwano, M., et al. (2002). p73 Interacts with c-Myc to regulate Y-box-binding protein-1 expression. J. Biol. Chem. 277, 31694-31702. doi: 10.1074/jbc.m200266200

van Roeyen, C. R., Scurt, F. G., Brandt, S., Kuhl, V. A., Martinkus, S., Djudjaj, S., et al. (2013). Cold shock Y-box protein-1 proteolysis autoregulates its transcriptional activities. Cell Commun. Signal. 11:63. doi: 10.1186/1478-811X11-63

van Zandwijk, N., Pavlakis, N., Kao, S. C., Linton, A., Boyer, M. J., Clarke, S., et al. (2017). Safety and activity of microRNA-loaded minicells in patients with recurrent malignant pleural mesothelioma: a first-in-man, phase 1, openlabel, dose-escalation study. Lancet Oncol. 18, 1386-1396. doi: 10.1016/S14702045(17)30621-6
Vanni, I., Alama, A., Grossi, F., Dal Bello, M. G., and Coco, S. (2017). Exosomes: a new horizon in lung cancer. Drug Discov. Today 22, 927-936. doi: 10.1016/j. drudis.2017.03.004

Ventola, C. L. (2017). Cancer immunotherapy, part 3: challenges and future trends. Pharm. Ther. 42, 514-521.

Visconti, R., Morra, F., Guggino, G., and Celetti, A. (2017). The between now and then of lung cancer chemotherapy and immunotherapy. Int. J. Mol. Sci. 18:E1374

Vogelzang, N. J., Rusthoven, J. J., Symanowski, J., Denham, C., Kaukel, E., Ruffie, P., et al. (2003). Phase III study of pemetrexed in combination with cisplatin versus cisplatin alone in patients with malignant pleural mesothelioma. J. Clin. Oncol. 21, 2636-2644. doi: 10.1200/jco.2003.11.136

Volm, M., and Koomagi, R. (2000). Prognostic relevance of c-Myc and caspase-3 for patients with non-small cell lung cancer. Oncol. Rep. 7, 95-103.

Wang, H., Sun, R., Chi, Z., Li, S., and Hao, L. (2017). Silencing of Y-box binding protein- 1 by RNA interference inhibits proliferation, invasion, and metastasis, and enhances sensitivity to cisplatin through NF-KB signaling pathway in human neuroblastoma SH-SY5Y cells. Mol. Cell. Biochem. 433, 1-12. doi: 10.1007/s11010-017-3011-3

Wang, W., Ke, S., Chen, G., Gao, Q., Wu, S., Wang, S., et al. (2004). Effect of lung resistance-related protein on the resistance to cisplatin in human ovarian cancer cell lines. Oncol. Rep. 12, 1365-1370.

Wang, W., Zheng, Y., Jia, J., Li, C., Duan, Q., Li, R., et al. (2017). Antimicrobial peptide LL-37 promotes the viability and invasion of skin squamous cell carcinoma by upregulating YB-1. Exp. Ther. Med. 14, 499-506. doi: 10.3892/ etm.2017.4546

Wang, Y., Wu, J., Yang, Y., Wei, Y., Peng, X., Chen, R., et al. (2018). miR-216a$5 \mathrm{p}$ inhibits malignant progression in small cell lung cancer: involvement of the Bcl-2 family proteins. Cancer Manag. Res. 10, 4735-4745. doi: 10.2147/CMAR. S178380

Wangari-Talbot, J., and Hopper-Borge, E. (2013). Drug resistance mechanisms in non-small cell lung carcinoma. J. Cancer Res. Updates 2, 265-282.

Weeraratna, A. T., Jiang, Y., Hostetter, G., Rosenblatt, K., Duray, P., Bittner, M., et al. (2002). Wnt5a signaling directly affects cell motility and invasion of metastatic melanoma. Cancer Cell 1, 279-288. doi: 10.1016/s1535-6108(02) 00045-4

Wei, M.-M., Zhou, Y.-C., Wen, Z.-S., Zhou, B., Huang, Y.-C., Wang, G.-Z., et al. (2016). Long non-coding RNA stabilizes the Y-box-binding protein 1 and regulates the epidermal growth factor receptor to promote lung carcinogenesis. Oncotarget 7, 59556-59571. doi: 10.18632/oncotarget.10006

Wen, Z.-M., Jie, J., Zhang, Y., Liu, H., and Peng, L.-P. (2017). A self-assembled polyjuglanin nanoparticle loaded with doxorubicin and anti-Kras siRNA for attenuating multidrug resistance in human lung cancer. Biochem. Biophys. Res. Commun. 493, 1430-1437. doi: 10.1016/j.bbrc.2017.09.132

Winther-Larsen, A., Fynboe Ebert, E. B., Meldgaard, P., and Sorensen, B. S. (2019). EGFR gene polymorphism predicts improved outcome in patients With EGFR mutation-positive non-small cell lung cancer treated with erlotinib. Clin. Lung Cancer 20, 161.e1-166.e1. doi: 10.1016/j.cllc.2019.02.011

Wolffe, A., Tafuri, S., Ranjan, M., and Familari, M. (1992). The Y-box factors: a family of nucleic acid binding proteins conserved from Escherichia coli to man. New Biol. 4, 290-298.

Woolley, A. G., Algie, M., Samuel, W., Harfoot, R., Wiles, A., Hung, N. A., et al. (2011). Prognostic association of YB-1 expression in breast cancers: a matter of antibody. PLoS One 6:e20603. doi: 10.1371/journal.pone.0020603

Wu, Q., Cheng, Z., Zhu, J., Xu, W., Peng, X., Chen, C., et al. (2015). Suberoylanilide hydroxamic acid treatment reveals crosstalks among proteome, ubiquitylome and acetylome in non-small cell lung cancer A549 cell line. Sci. Rep. 5:9520. doi: 10.1038/srep09520

Xiao, H., Liu, Y., Liang, P., Wang, B., Tan, H., Zhang, Y., et al. (2018). TP53TG1 enhances cisplatin sensitivity of non-small cell lung cancer cells through regulating miR-18a/PTEN axis. Cell Biosci. 8:23. doi: 10.1186/s13578-0180221-7

$\mathrm{Xu}, \mathrm{J}$., and $\mathrm{Hu}, \mathrm{Z}$. (2016). Y-box-binding protein 1 promotes tumor progression and inhibits cisplatin chemosensitivity in esophageal squamous cell carcinoma. Biomed. Pharmacother. 79, 17-22. doi: 10.1016/j.biopha.2016.01.037

Xu, L., Fu, Y., Li, Y., and Han, X. (2017a). Cisplatin induces expression of drug resistance-related genes through $\mathrm{c}$-jun $\mathrm{N}$-terminal kinase pathway in human 
lung cancer cells. Cancer Chemother. Pharmacol. 80, 235-242. doi: 10.1007/ s00280-017-3355-0

Xu, L., Li, H., Wu, L., and Huang, S. (2017b). YBX1 promotes tumor growth by elevating glycolysis in human bladder cancer. Oncotarget 8, 65946-65956. doi: 10.18632/oncotarget.19583

Xu, M., Jin, H., Xu, C.-X., Sun, B., Song, Z.-G., Bi, W.-Z., et al. (2015). miR382 inhibits osteosarcoma metastasis and relapse by targeting $\mathrm{Y}$ box-binding protein 1. Mol. Ther. 23, 89-98. doi: 10.1038/mt.2014.197

Yahata, H., Kobayashi, H., Kamura, T., Amada, S., Hirakawa, T., Kohno, K., et al. (2002). Increased nuclear localization of transcription factor YB-1 in acquired cisplatin-resistant ovarian cancer. J. Cancer Res. Clin. Oncol. 128, 621-626. doi: 10.1007/s00432-002-0386-6

Yamashita, T., Higashi, M., Momose, S., Morozumi, M., and Tamaru, J.-I. (2017). Nuclear expression of Y box binding-1 is important for resistance to chemotherapy including gemcitabine in TP53-mutated bladder cancer. Int. J. Oncol. 51, 579-586. doi: 10.3892/ijo.2017.4031

Yang, H., Rivera, Z., Jube, S., Nasu, M., Bertino, P., Goparaju, C., et al. (2010). Programmed necrosis induced by asbestos in human mesothelial cells causes high-mobility group box 1 protein release and resultant inflammation. Proc. Natl. Acad. Sci. U.S.A. 107, 12611-12616. doi: 10.1073/pnas.1006542107

Yang, Y.-R., Li, Y.-X., Gao, X.-Y., Zhao, S.-S., Zang, S.-Z., and Zhang, Z.-Q. (2015). MicroRNA-137 inhibits cell migration and invasion by targeting bone morphogenetic protein-7 (BMP7) in non-small cell lung cancer cells. Int. J. Clin. Exp. Pathol. 8, 10847-10853.

Yap, T. A., Aerts, J. G., Popat, S., and Fennell, D. A. (2017). Novel insights into mesothelioma biology and implications for therapy. Nat. Rev. Cancer 17, 475-488. doi: 10.1038/nrc.2017.42

Yokoyama, H., Harigae, H., Takahashi, S., Takahashi, S., Furuyama, K., Kaku, M., et al. (2003). Regulation of YB-1 gene expression by GATA transcription factors. Biochem. Biophys. Res. Commun. 303, 140-145. doi: 10.1016/s0006-291x(03) 00296- 1

Yuan, Z.-Q., Chen, W.-L., You, B.-G., Liu, Y., Li, J.-Z., Zhu, W.-J., et al. (2017). Multifunctional nanoparticles co-delivering EZH2 siRNA and etoposide for synergistic therapy of orthotopic non-small-cell lung tumor. J. Control. Release 268, 198-211. doi: 10.1016/j.jconrel.2017.10.025

Zarogoulidis, K., Ziogas, E., Boutsikou, E., Zarogoulidis, P., Darwiche, K., Kontakiotis, T., et al. (2013). Immunomodifiers in combination with conventional chemotherapy in small cell lung cancer: a phase II, randomized study. Drug Design Dev. Ther. 7, 611-617. doi: 10.2147/DDDT.S43184

Zarogoulidis, P., Lampaki, S., Turner, J., Huang, H., Kakolyris, S., and Syrigos, K. (2014). mTOR pathway: a current, up-to-date mini-review (Review). Oncol. Lett. 8, 2367-2370. doi: 10.3892/ol.2014.2608
Zhao, S., Wang, Y., Guo, T., Yu, W., Li, J., Tang, Z., et al. (2016). YBX1 regulates tumor growth via CDC25a pathway in human lung adenocarcinoma. Oncotarget 7, 82139-82157. doi: 10.18632/oncotarget.10080

Zhen, Q., Gao, L.-N., Wang, R.-F., Chu, W.-W., Zhang, Y.-X., Zhao, X.J., et al. (2018). LncRNA DANCR promotes lung cancer by sequestering miR-216a. Cancer Control 25:1073274818769849. doi: 10.1177/10732748187 69849

Zheng, J., Jing, W., and Orentas, R. J. (2009). Discovery of YB-1 as a new immunological target in neuroblastoma by vaccination in the context of regulatory T cell blockade. Acta Biochim. Biophys. Sin. 41, 980-990. doi: 10. 1093/abbs/gmp092

Zheng, J., Liu, P., and Yang, X. (2012). YB-1 immunization combined with regulatory $\mathrm{T}$-cell depletion induces specific $\mathrm{T}$-cell responses that protect against neuroblastoma in the early stage. Acta Biochim. Biophys. Sin. 44, 1006-1014. doi: 10.1093/abbs/gms089

Zhou, L., Lv, T., Zhang, Q., Zhu, Q., Zhan, P., Zhu, S., et al. (2017a). The biology, function and clinical implications of exosomes in lung cancer. Cancer Lett. 407, 84-92. doi: 10.1016/j.canlet.2017.08.003

Zhou, L.-L., Ni, J., Feng, W.-T., Yao, R., Yue, S., Zhu, Y.-N., et al. (2017b). High YBX1 expression indicates poor prognosis and promotes cell migration and invasion in nasopharyngeal carcinoma. Exp. Cell Res. 361, 126-134. doi: 10. 1016/j.yexcr.2017.10.009

Zhou, S., Liu, L., Li, H., Eilers, G., Kuang, Y., Shi, S., et al. (2014). Multipoint targeting of the PI3K/mTOR pathway in mesothelioma. Br. J. Cancer 110, 2479-2488. doi: 10.1038/bjc.2014.220

Zong, D., Ouyang, R., Li, J., Chen, Y., and Chen, P. (2016). Notch signaling in lung diseases: focus on Notch1 and Notch3. Ther. Adv. Respir. Dis. 10, 468-484. doi: $10.1177 / 1753465816654873$

Conflict of Interest: GR has an issued patent, US 9,006,200, covering use of microRNAs for cancer therapy.

The remaining authors declare that the research was conducted in the absence of any commercial or financial relationships that could be construed as a potential conflict of interest.

Copyright (c) 2019 Johnson, Schelch, Mehta, Burgess and Reid. This is an open-access article distributed under the terms of the Creative Commons Attribution License (CC BY). The use, distribution or reproduction in other forums is permitted, provided the original author(s) and the copyright owner(s) are credited and that the original publication in this journal is cited, in accordance with accepted academic practice. No use, distribution or reproduction is permitted which does not comply with these terms. 